\title{
OPTICAL IMAGING IN RANDOM MEDIA: FROM SURGERY TO WAVE MASTERING
}

Sylvain GIGAN, Sébastien POPOFF, Jonas BINDING \& A. Claude BOCCARA

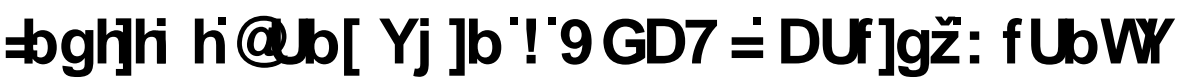




\section{OPTICAL IMAGING IN RANDOM MEDIA: FROM SURGERY TO WAVE MASTERING}

Sylvain GIGAN, Sébastien POPOFF, Jonas BINDING \& $\underline{A}$. Claude BOCCARA

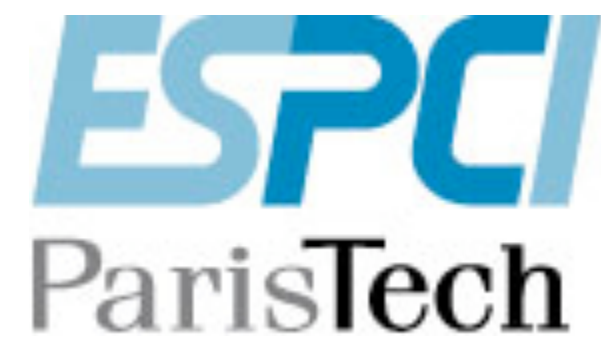

CARGESE JULY 12-15 th 2010 Summer School "Mesoscopic Physics in Complex Media"

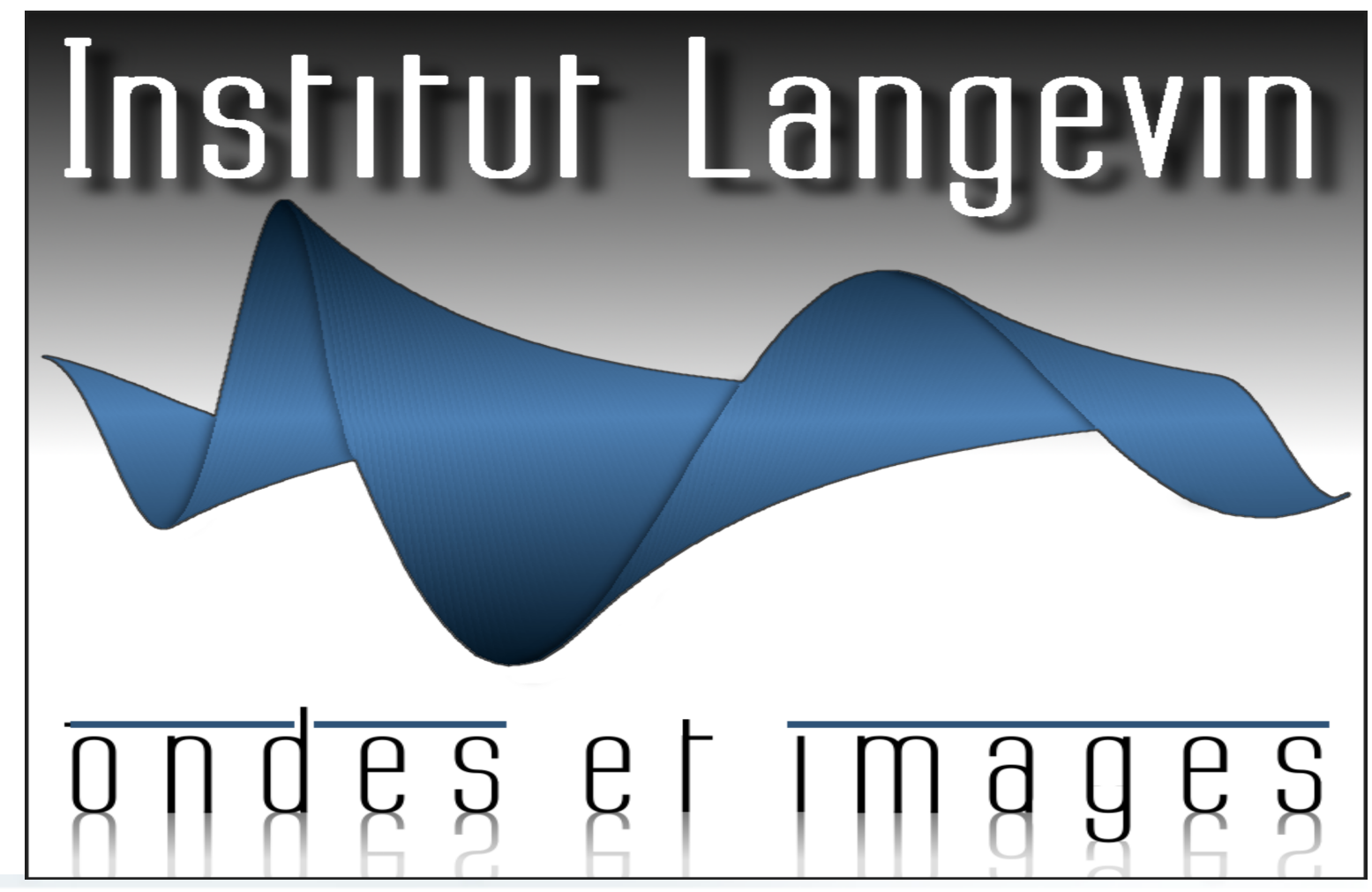

PAR! $S^{\text {univerite }}$ Inserm DIDEROT: 


\section{What is Institut Langevin? Where is it ?}

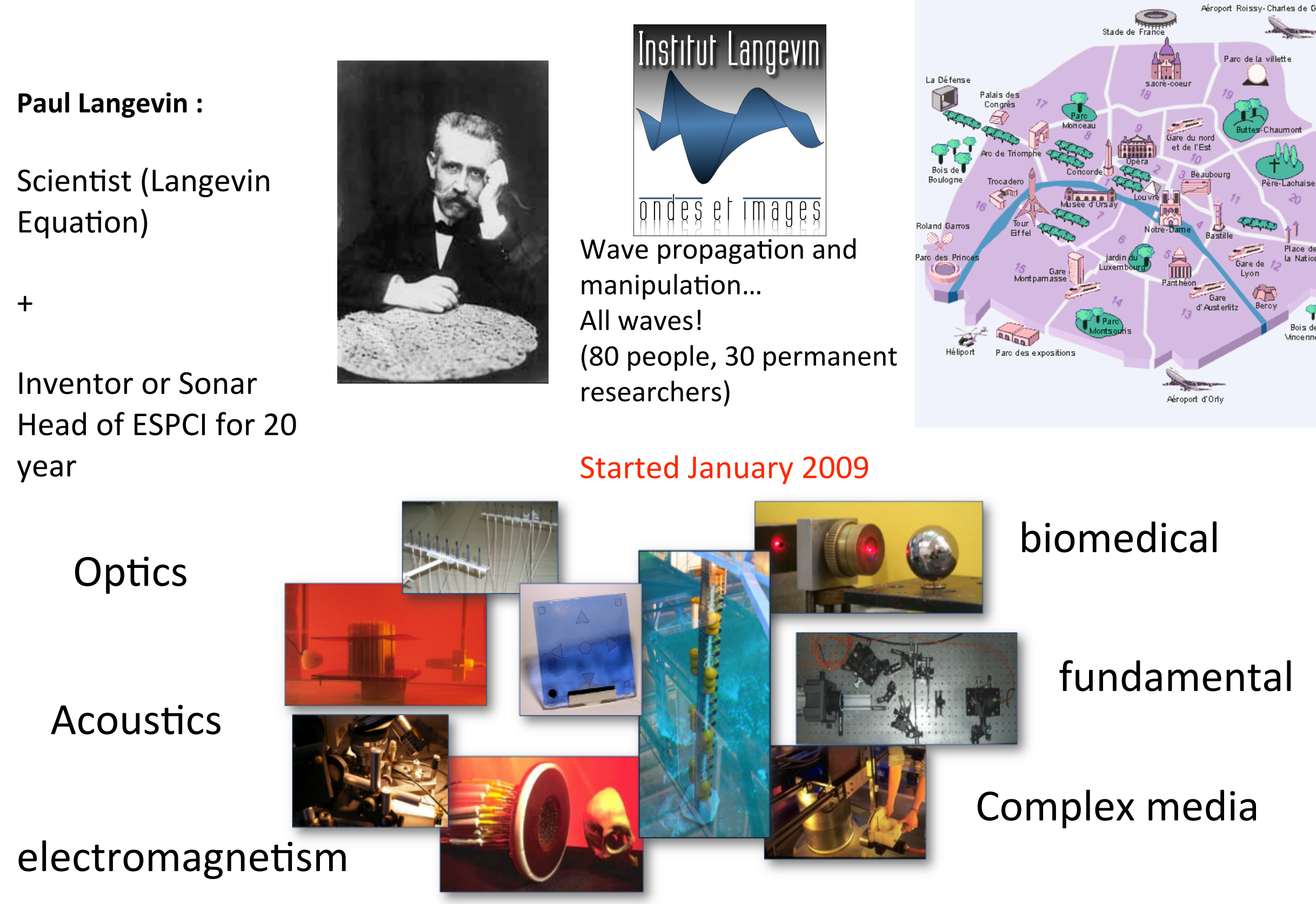




\section{IMAGINE AND IMAGING}

Photosource: designspongeonline.com

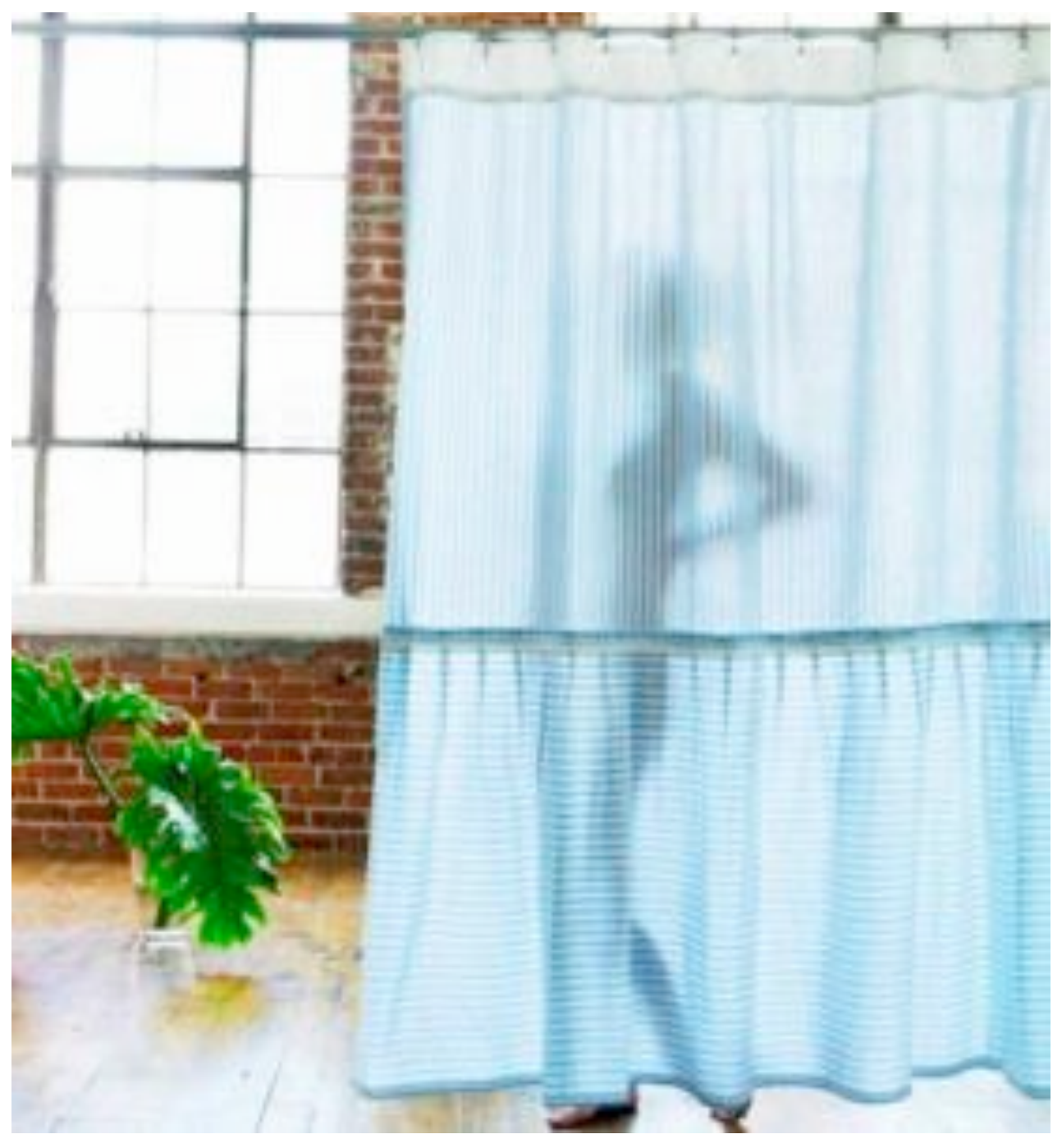

Model portfolio image from the official site for America's Next Top Model.

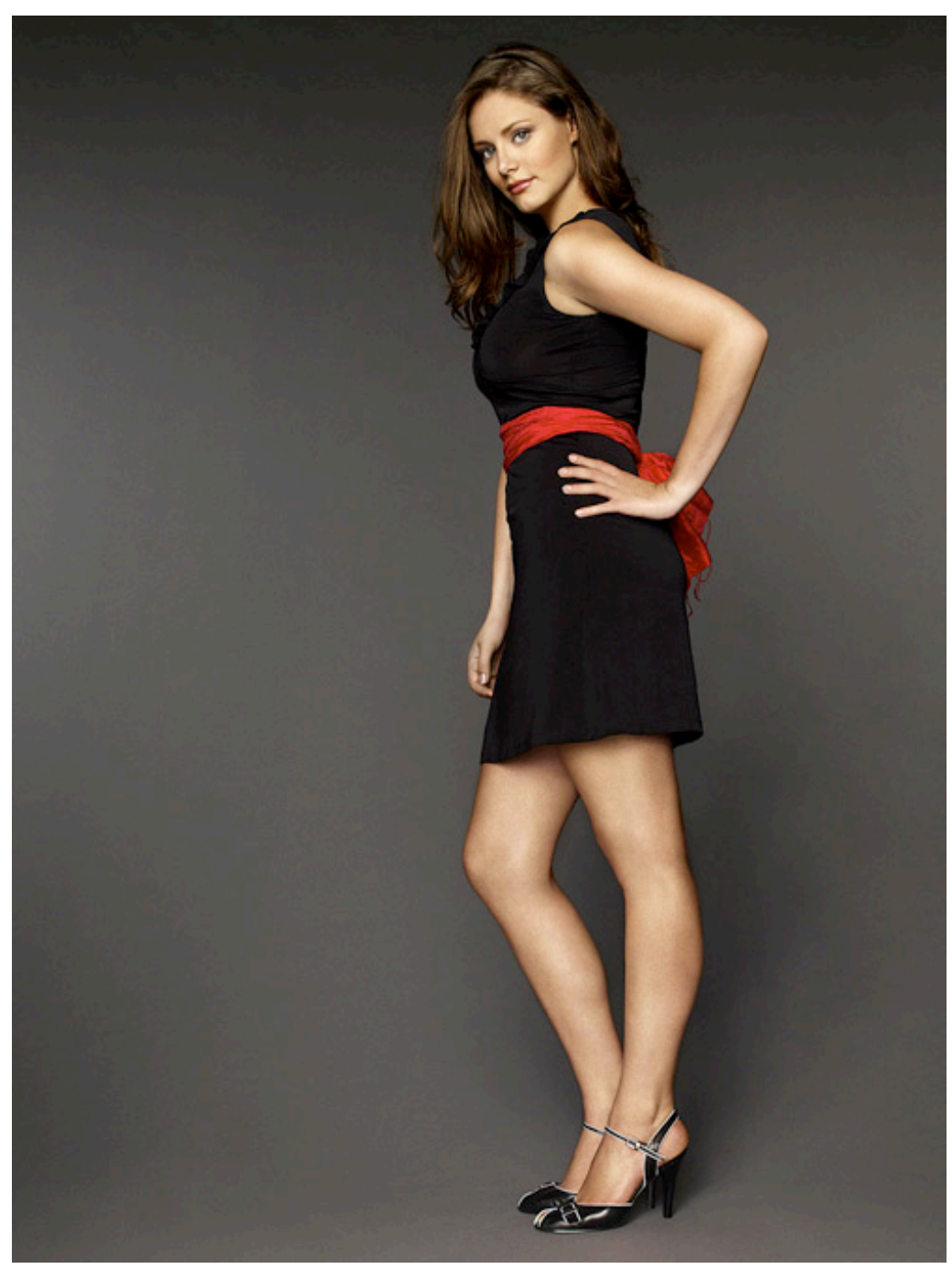




\section{OPTICAL IMAGING: WHICH SCALE?}

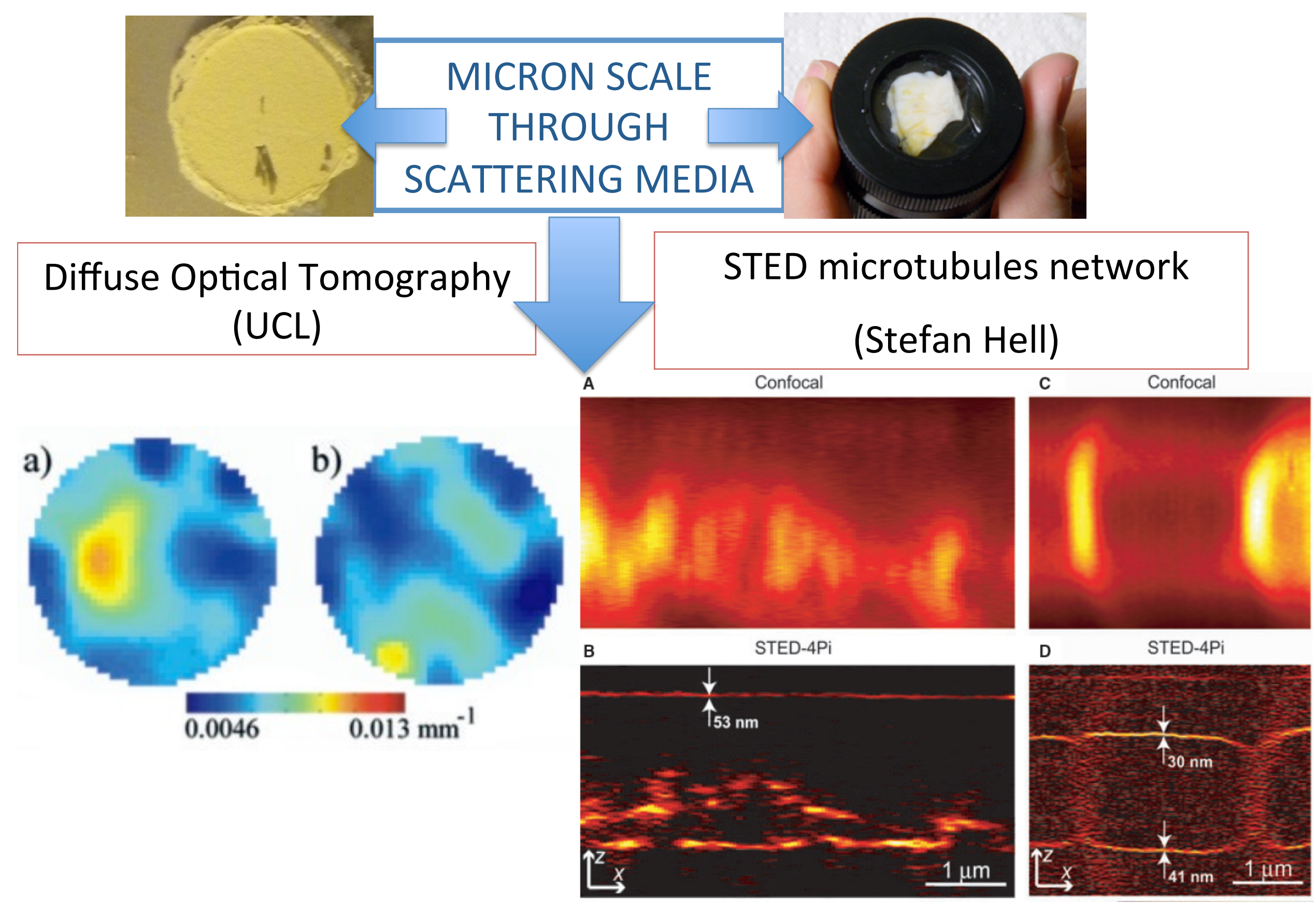




\section{TWO IMAGING APPROACHES}

Selection of balistic photons

SLICING VIRTUALLY

THROUGH TISSUES

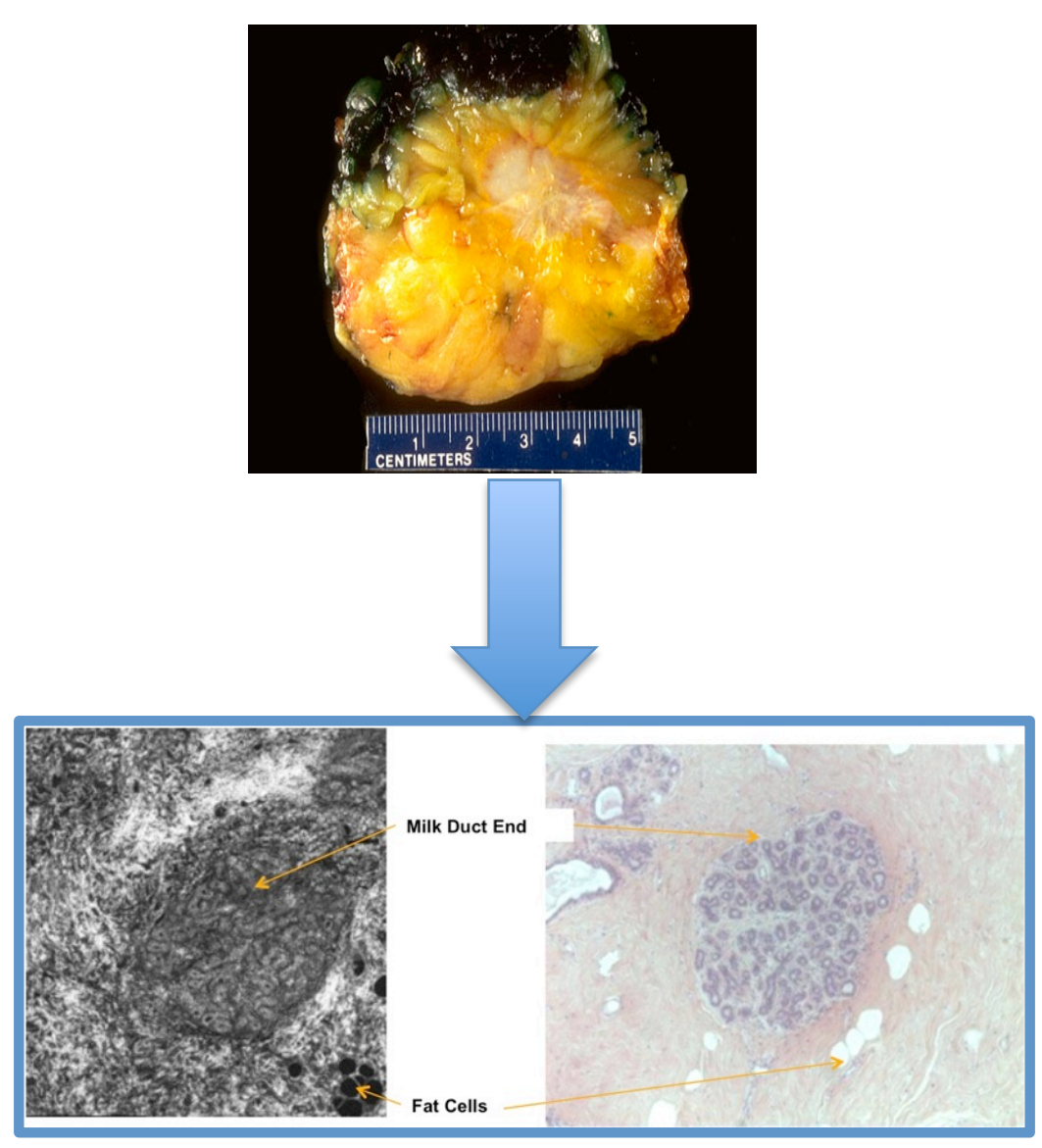

No more balistic light: seeing through an opaque wall

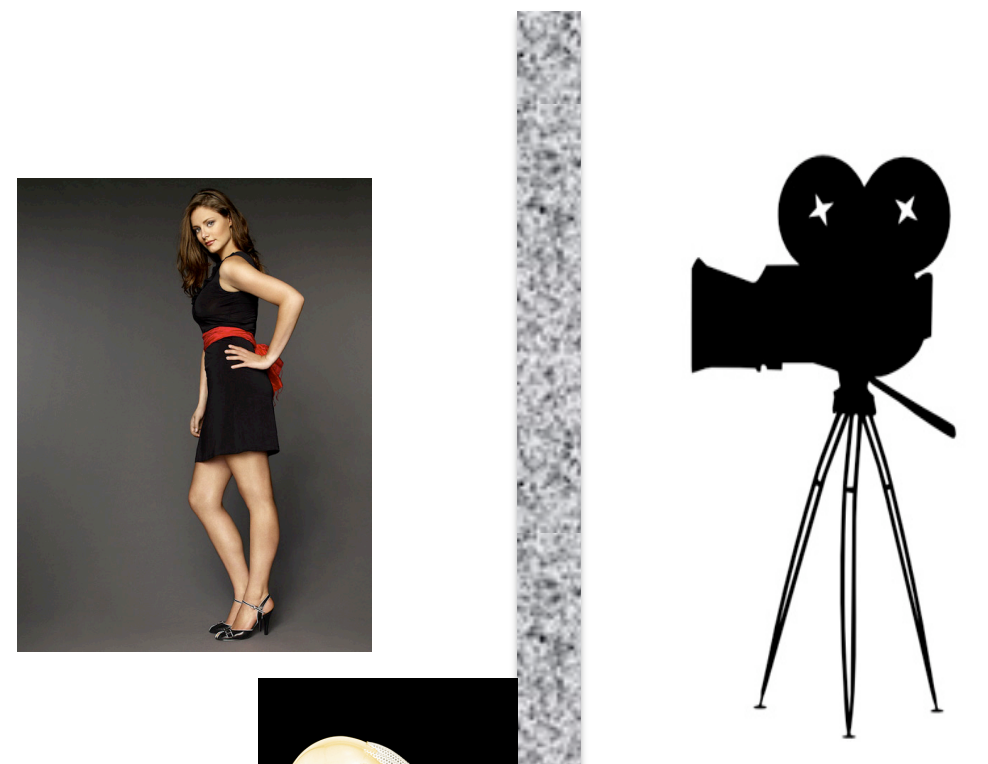




\section{The actors: transmission matrix}

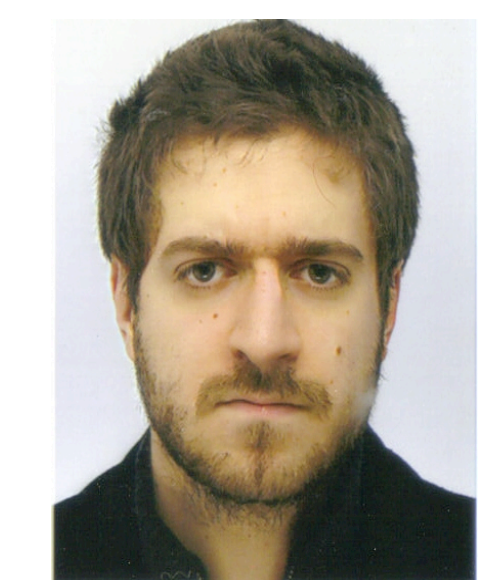

Sébastien POPOFF

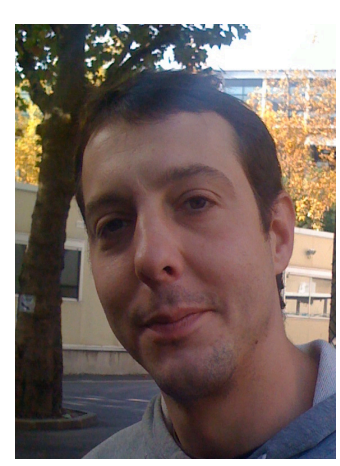

Geoffroy LEROSEY

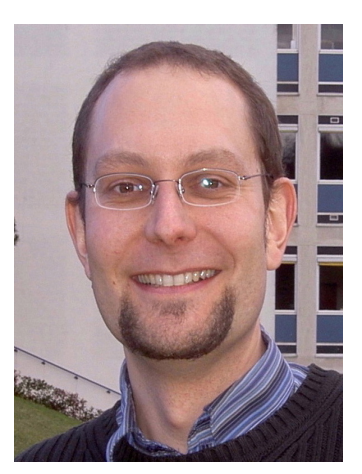

Rémi CARMINATI

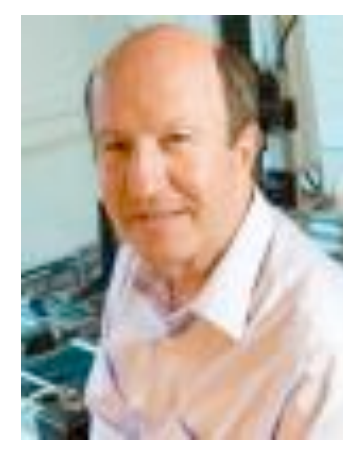

Mathias FINK

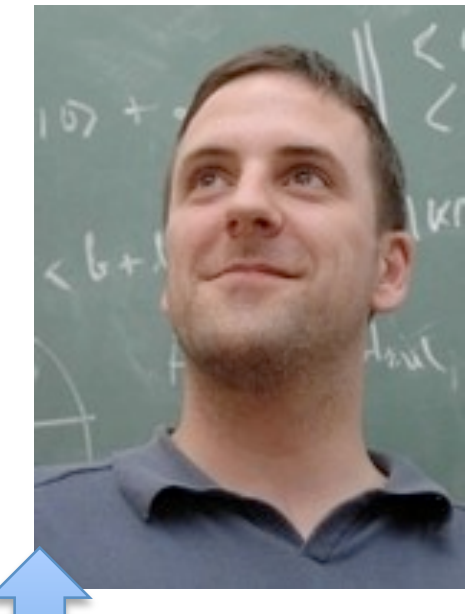

Sylvain GIGAN

\section{The inspirers}

Allard MOSK

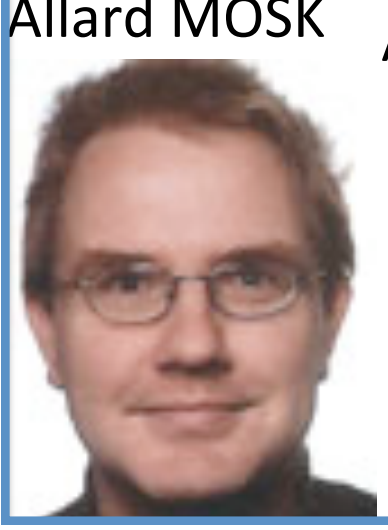

Ad LAGENDIK VELECOOP

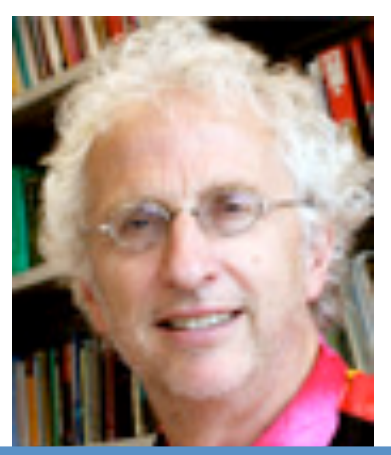

\section{Optical Tomography}

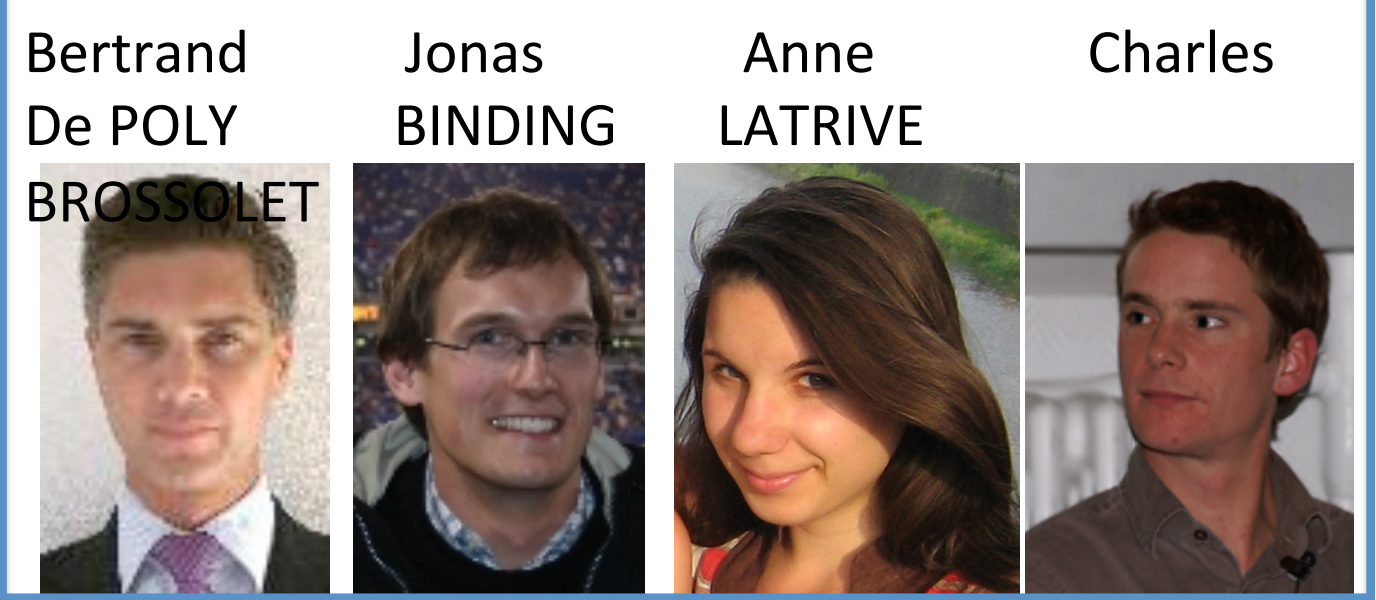




\section{TWO IMAGING APPROACHES}

Selection of balistic photons

SLICING VIRTUALLY

THROUGH TISSUES
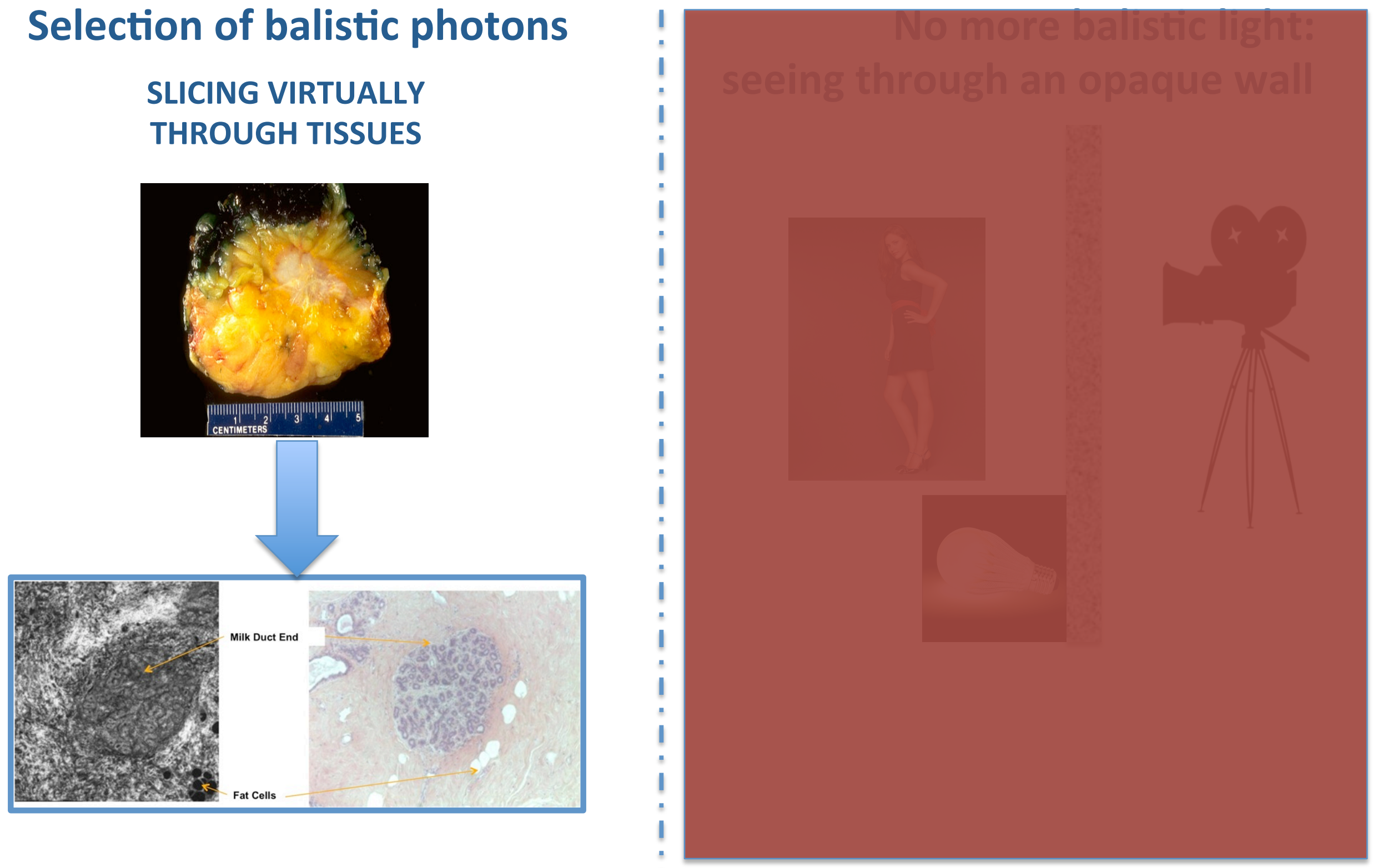


\section{Selection of balistic photons: why? Intra operative diagnostic}

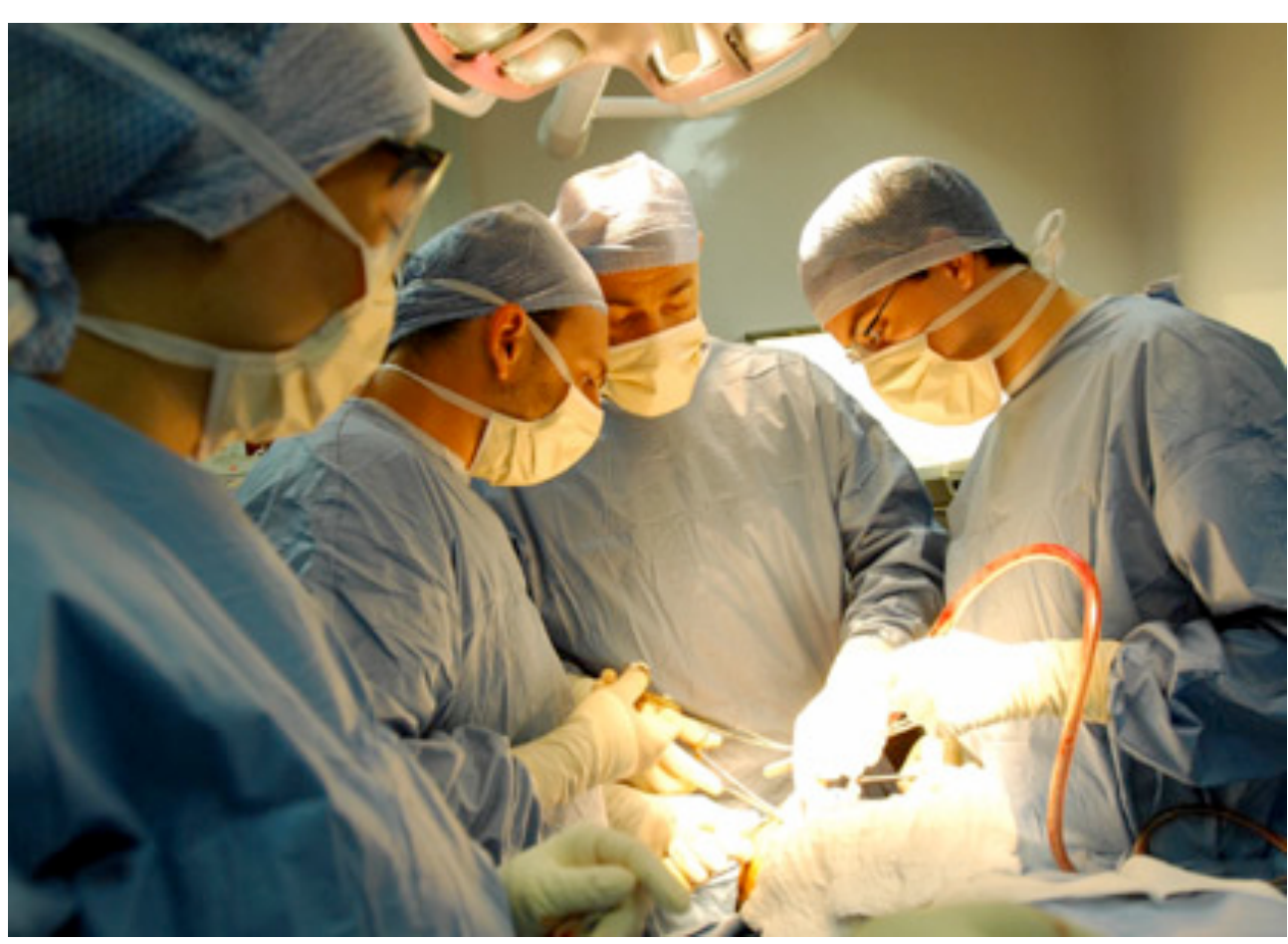

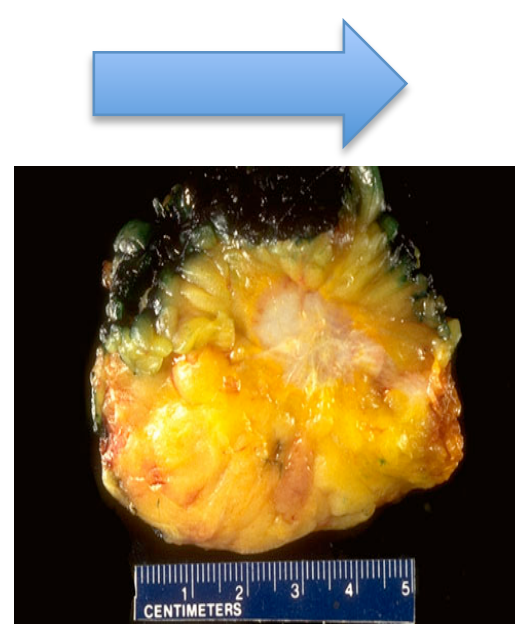

FAST DIAGNOSTIC 15' FEEDBACK

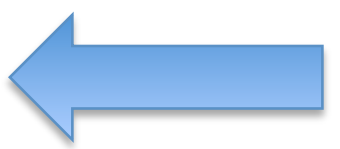

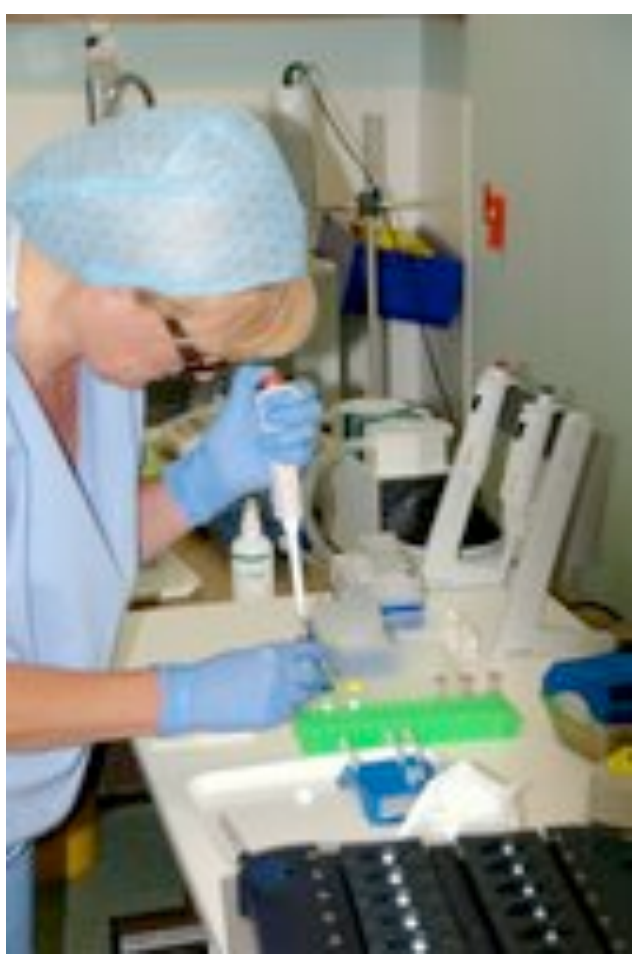

SLICING AND DETAILED ANALYSIS 1 TO 2 WEEKS FEEDBACK 


\section{A POSSIBLE STRATEGY}

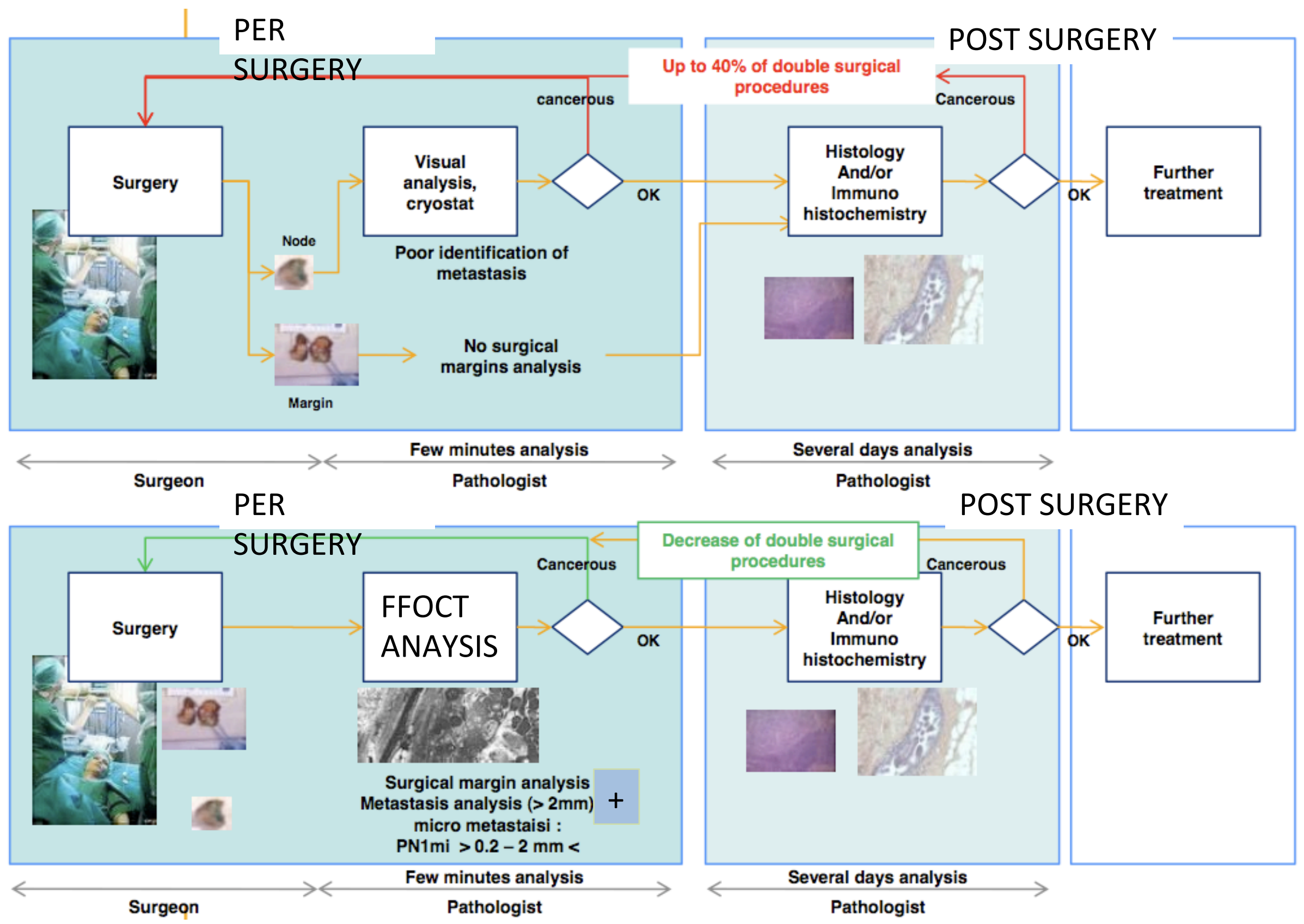




\section{EXPECTED BENEFITS}

- Reduction of patients pain

- Reduction of the cancer hospitals delays

- Reduction of the health costs

- Complementary non contact and non destructive diagnostics only

- The "gold standard" (pathologist's slices) analysis is still going on 


\section{In depth optical sectioning and pathology:}

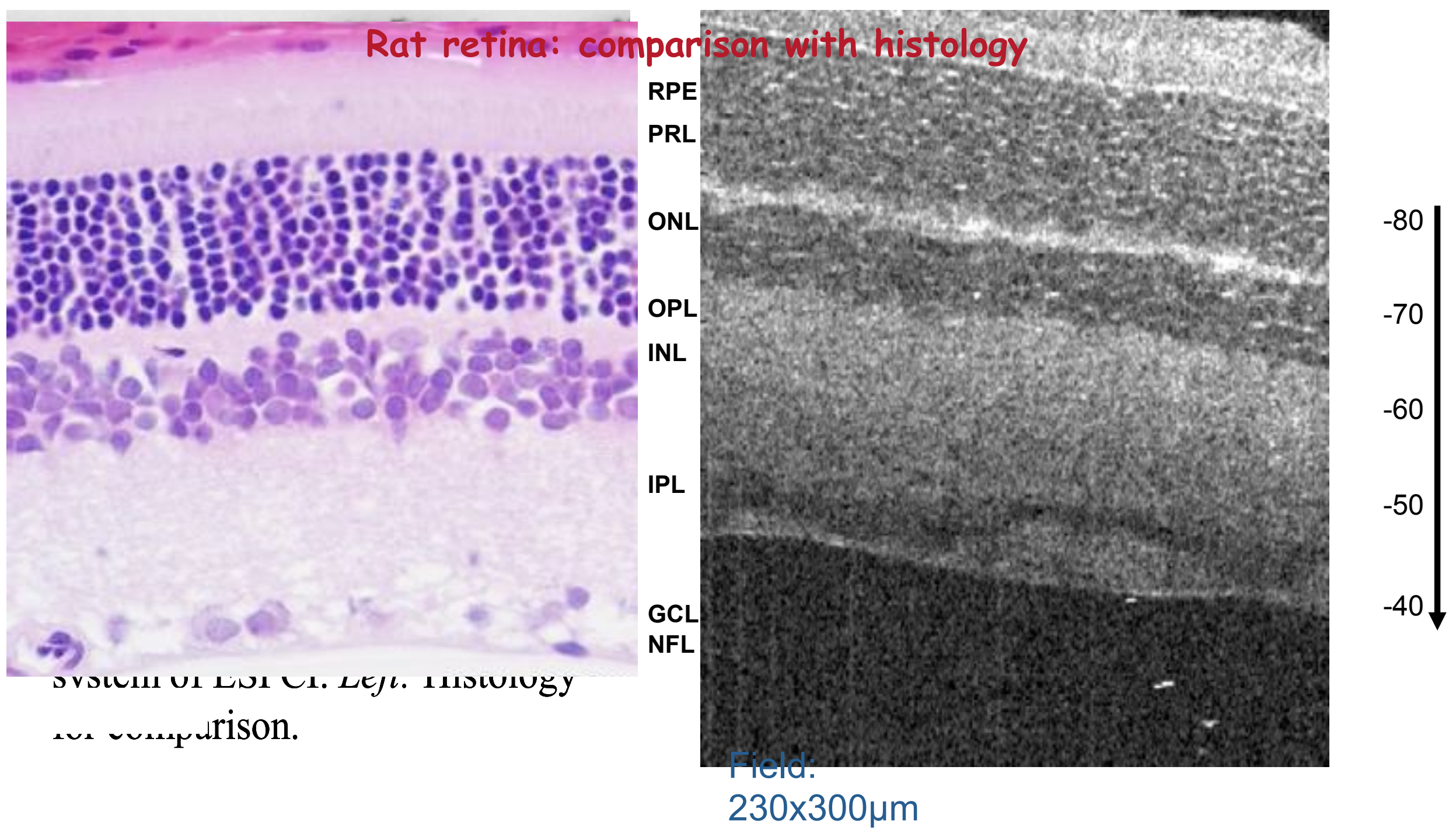

RPE: retinal pigmented epithelium. PRL: photoreceptor layer. ONL: outer nuclear layer. OPL: outer plexiforr layer. INL: inner nuclear layer. IPL: inner plexiform layer. GCL: ganglion cell layer. NFL: nerve fiber layer. 


\section{In depth optical sectioning and pathology:}

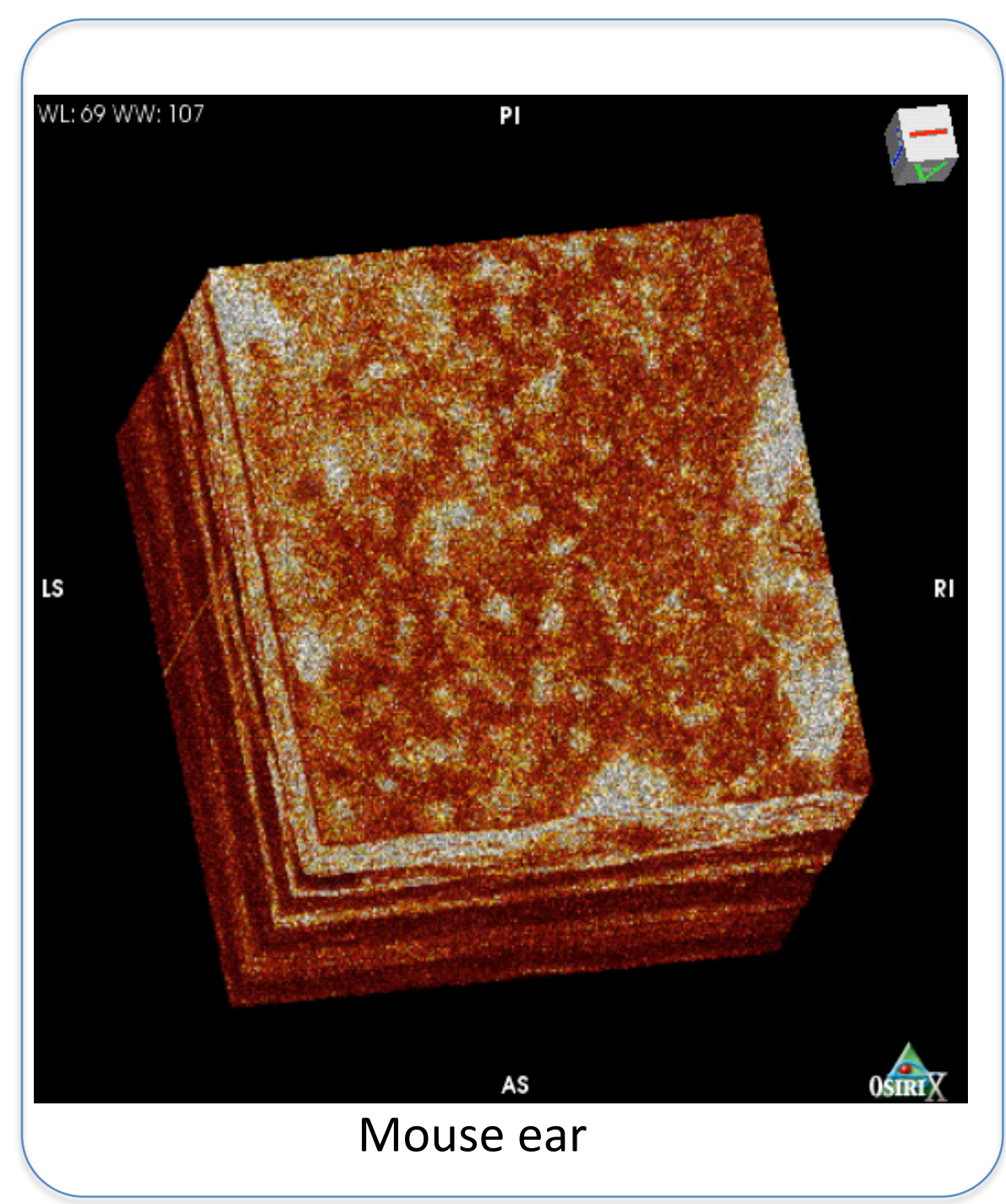




\section{In depth optical sectioning and pathology:}
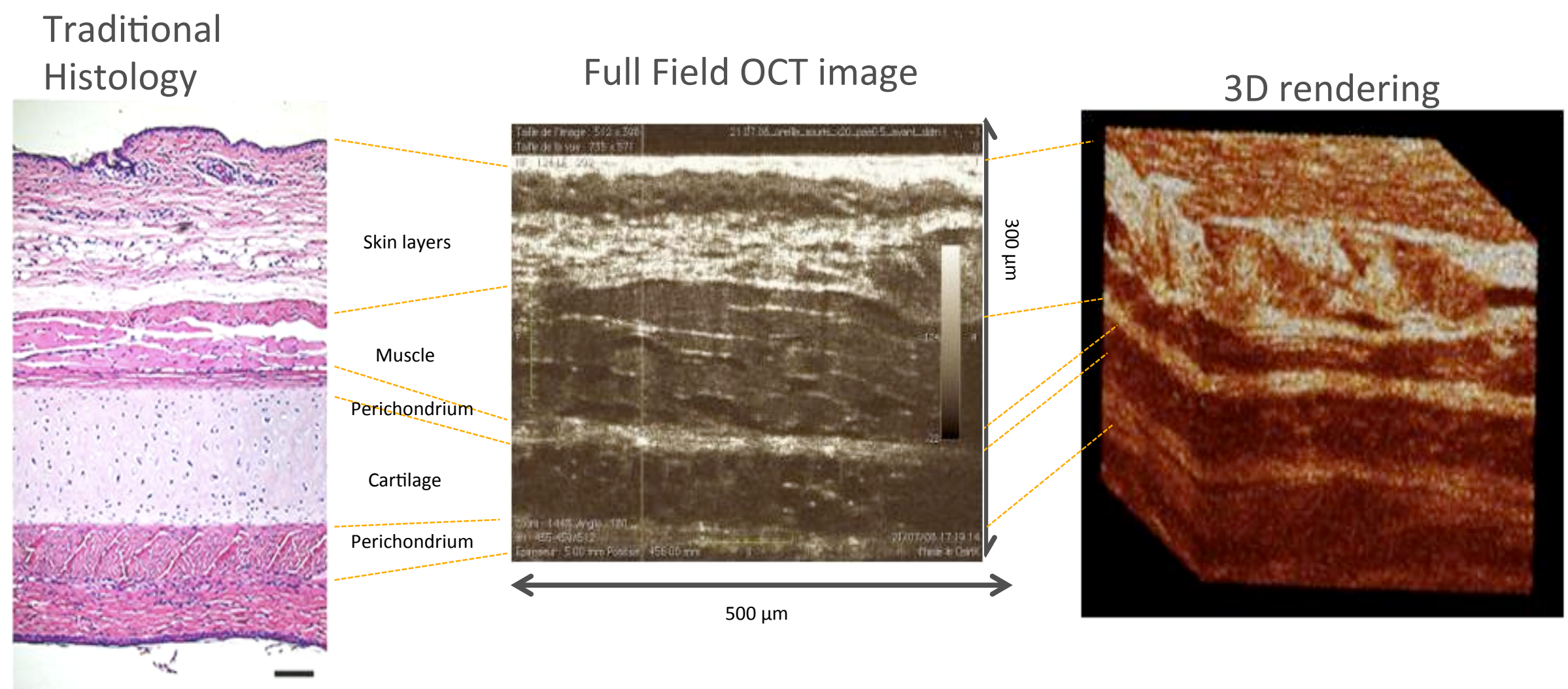


\section{OPTICAL COHERENCE TOMOGRAPHY: SELECTING BALISTIC PHOTONS}




\section{Balistic Photon Selection OCT = optical echography}

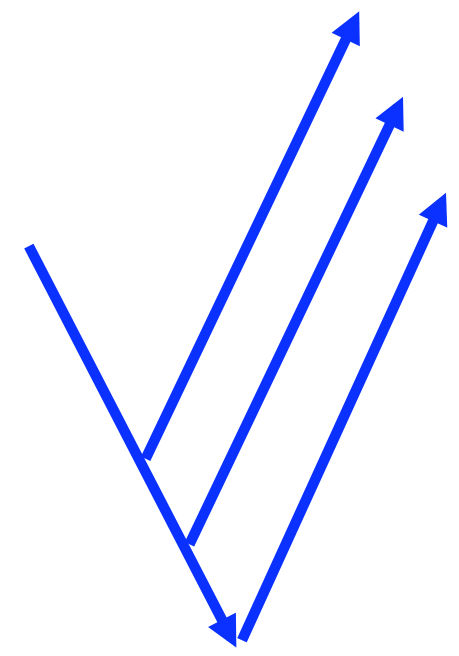

Fujimoto et al.

Ultrasound is replaced by light

Measurement of the amplitude and the travel time of backscattered light 


\section{Low coherence interferometry}

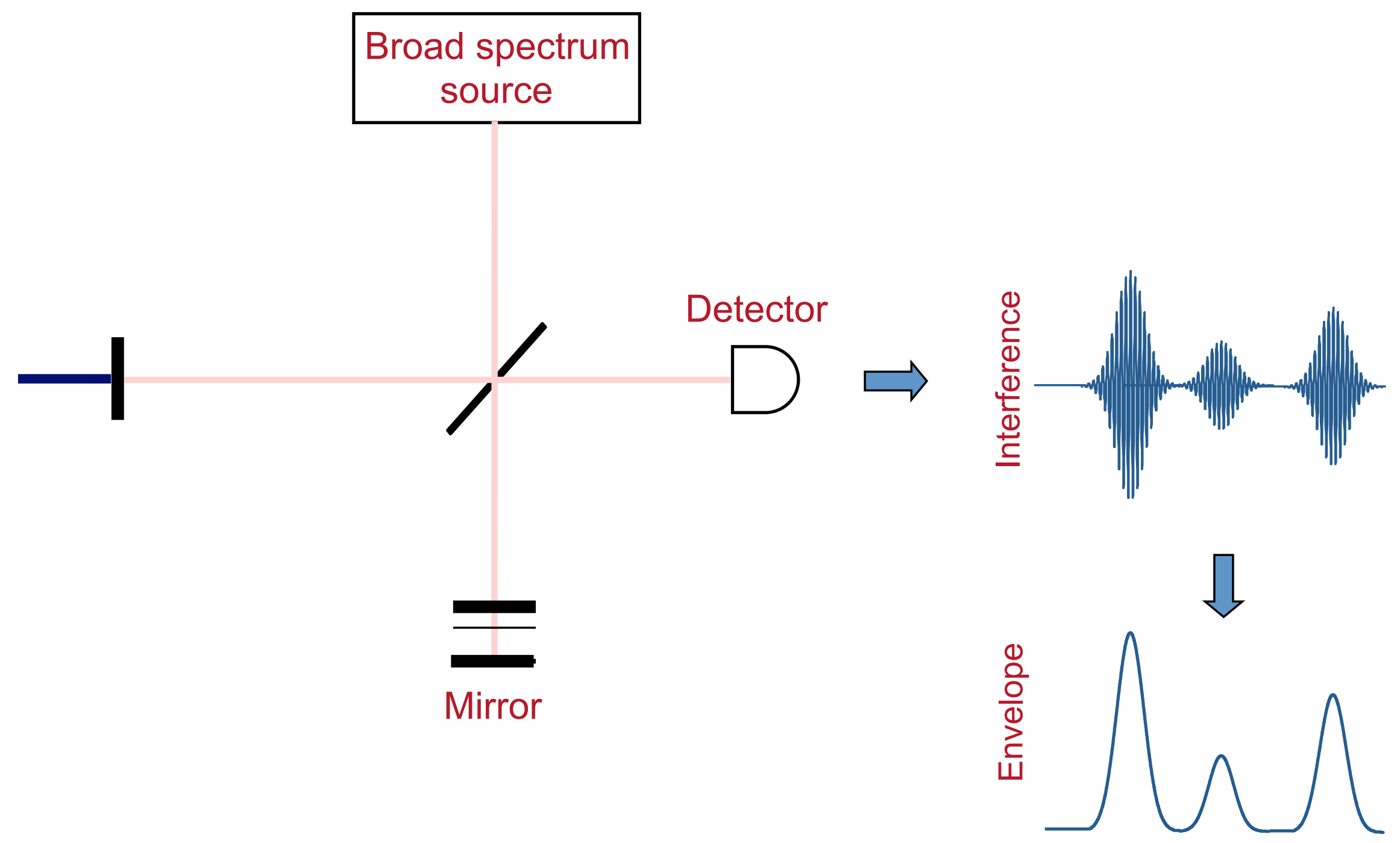




\section{Selection of ballistic photons}

\section{using low coherence interferometry}
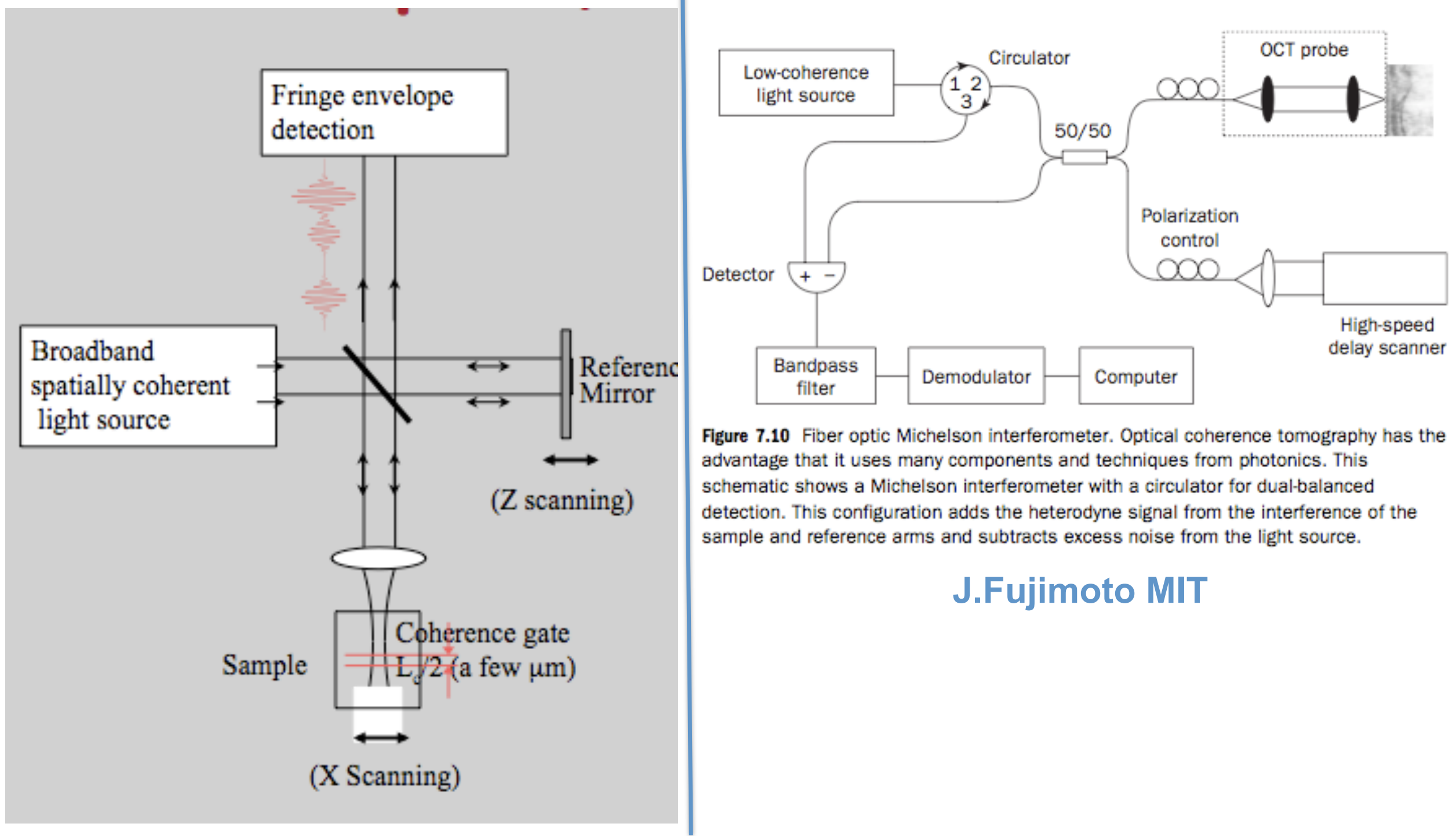

Figure 7.10 Fiber optic Michelson interferometer. Optical coherence tomography has the advantage that it uses many components and techniques from photonics. This schematic shows a Michelson interferometer with a circulator for dual-balanced detection. This configuration adds the heterodyne signal from the interference of the sample and reference arms and subtracts excess noise from the light source.

\section{J.Fujimoto MIT}




\section{Image of the retina}
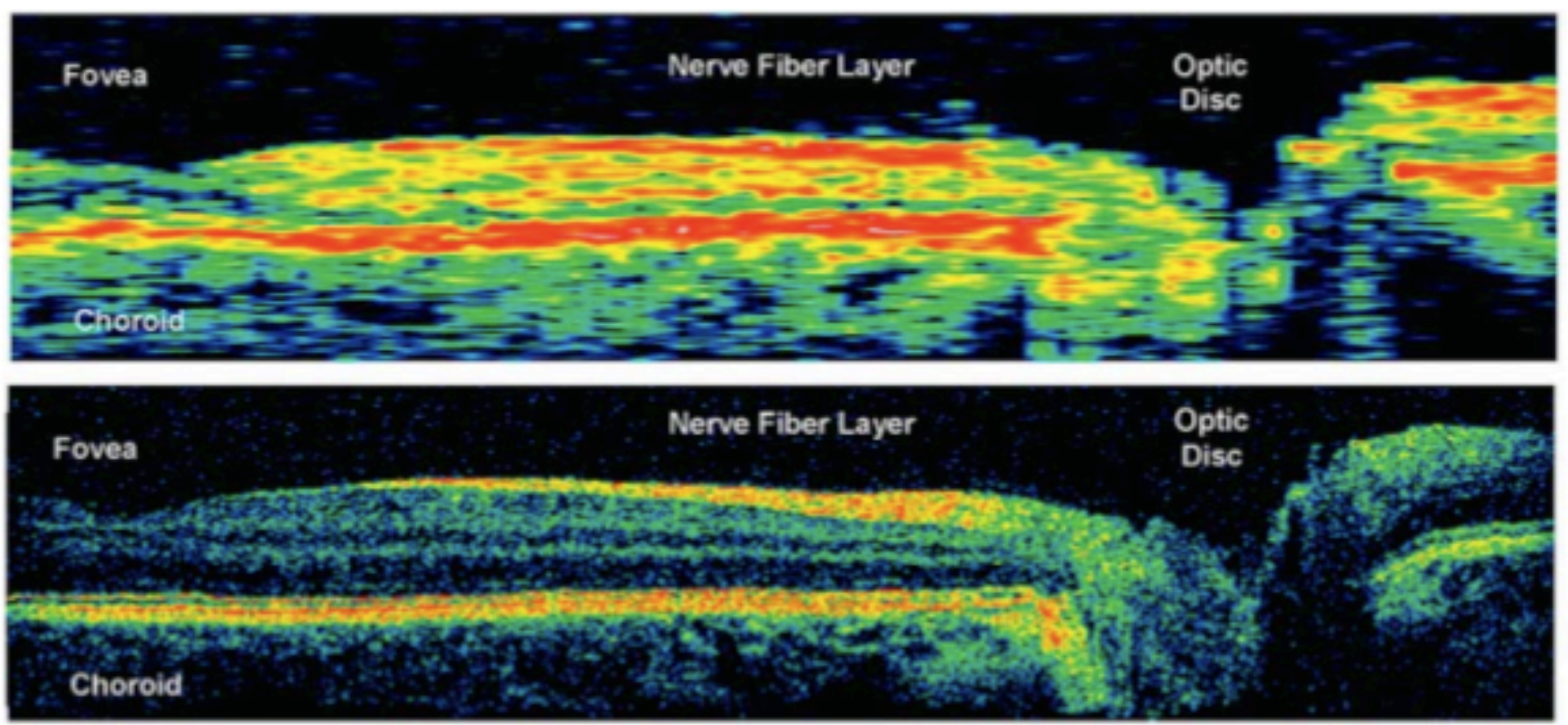

Figure 7.13 Comparison of standard and ultrahigh-resolution OCT images of the normal human retina. The axial resolution is $10 \mu \mathrm{m}$ using an SLD light source and $3 \mu \mathrm{m}$ using a femtosecond laser light source. The ultrahigh-resolution OCT image enables visualization of all major retinal layers (Drexler et al., 2001). 


\section{Image of the retina}

\section{Normal eye with intact fovea}

optical coherence tomography

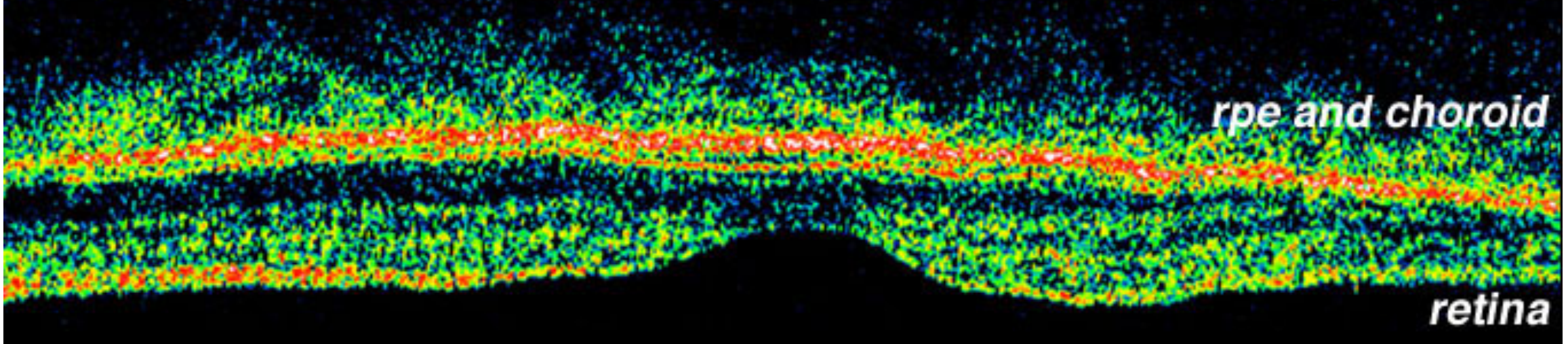

\section{Fellow eye with detached fovea}

webvision.umh. es/webvision/

ClinicalERG.htm Optical coherence tomography (OCT) images of the patient's normal macula and of the retina in the other eye with the macular detachment. 


\section{Principle of full field OCT}

SENSITIVITY $\approx 90 \mathrm{~dB}$ (1 backscattered photon over 1 billion) RESOLUTION $\approx 1 \mu \mathrm{m}$ in all directions

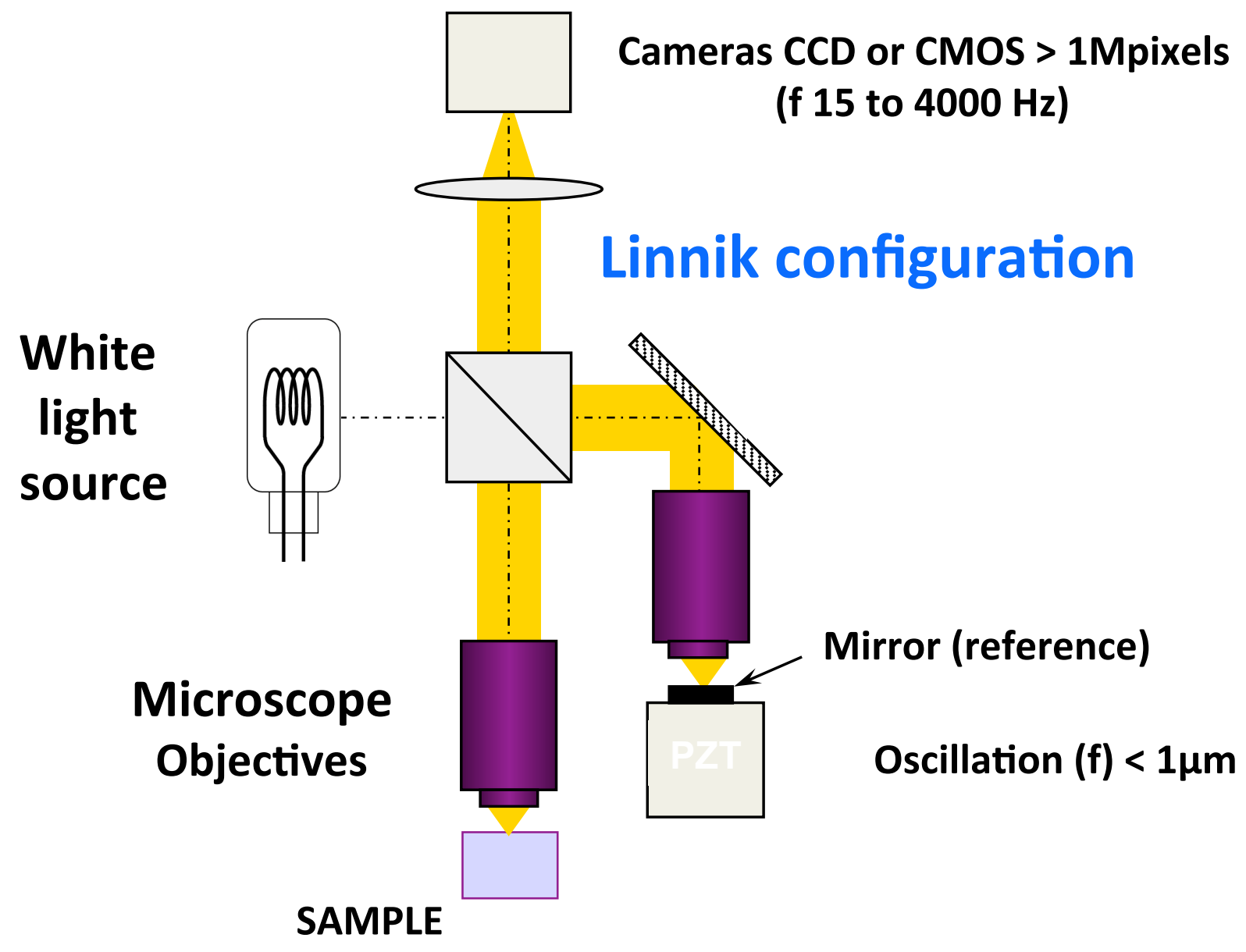




\section{Acquisition of the images}

\section{Tomographic Images en face (XY)}

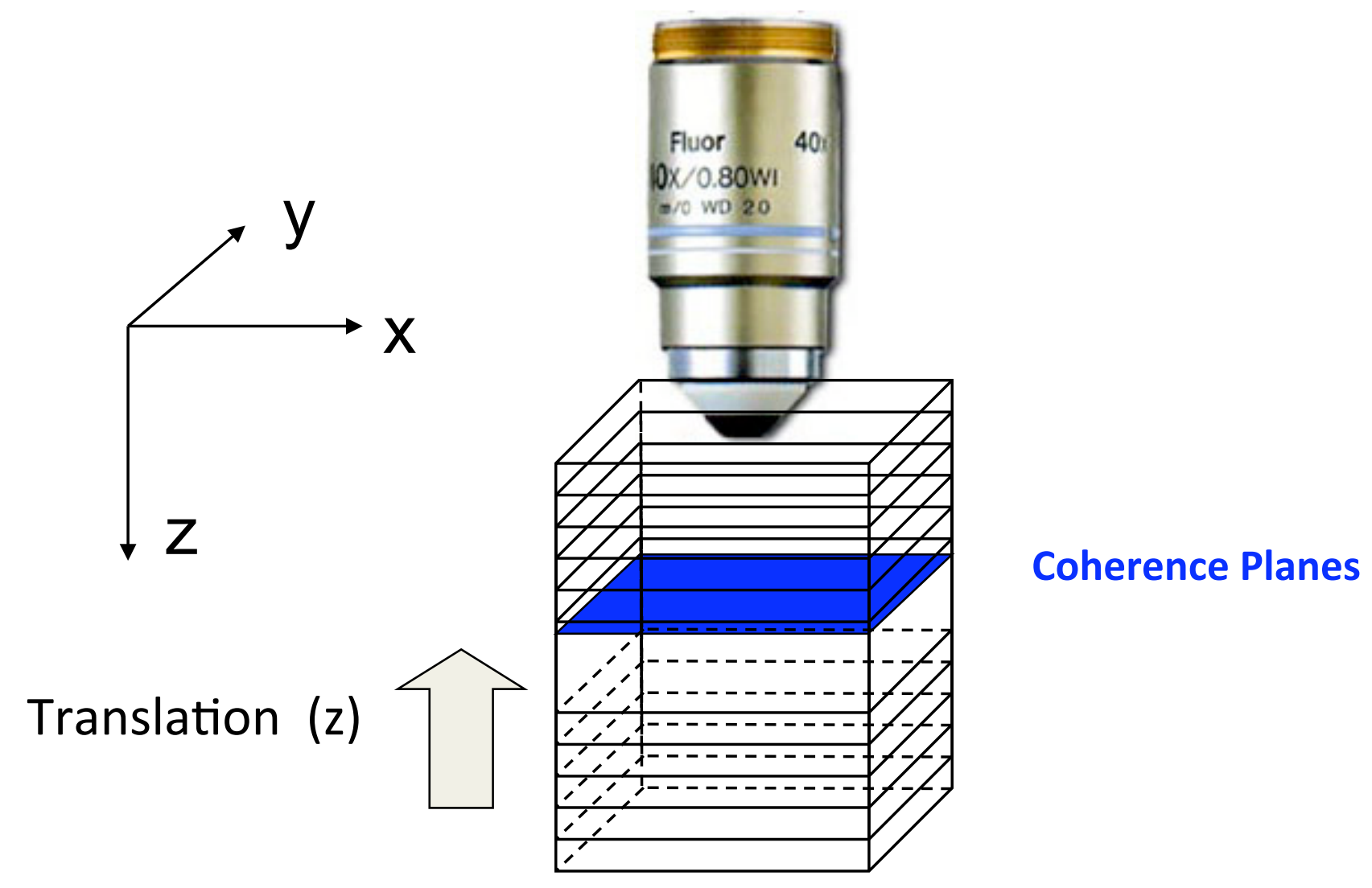


* Axial Resolution of Full Field OCT : Experiment
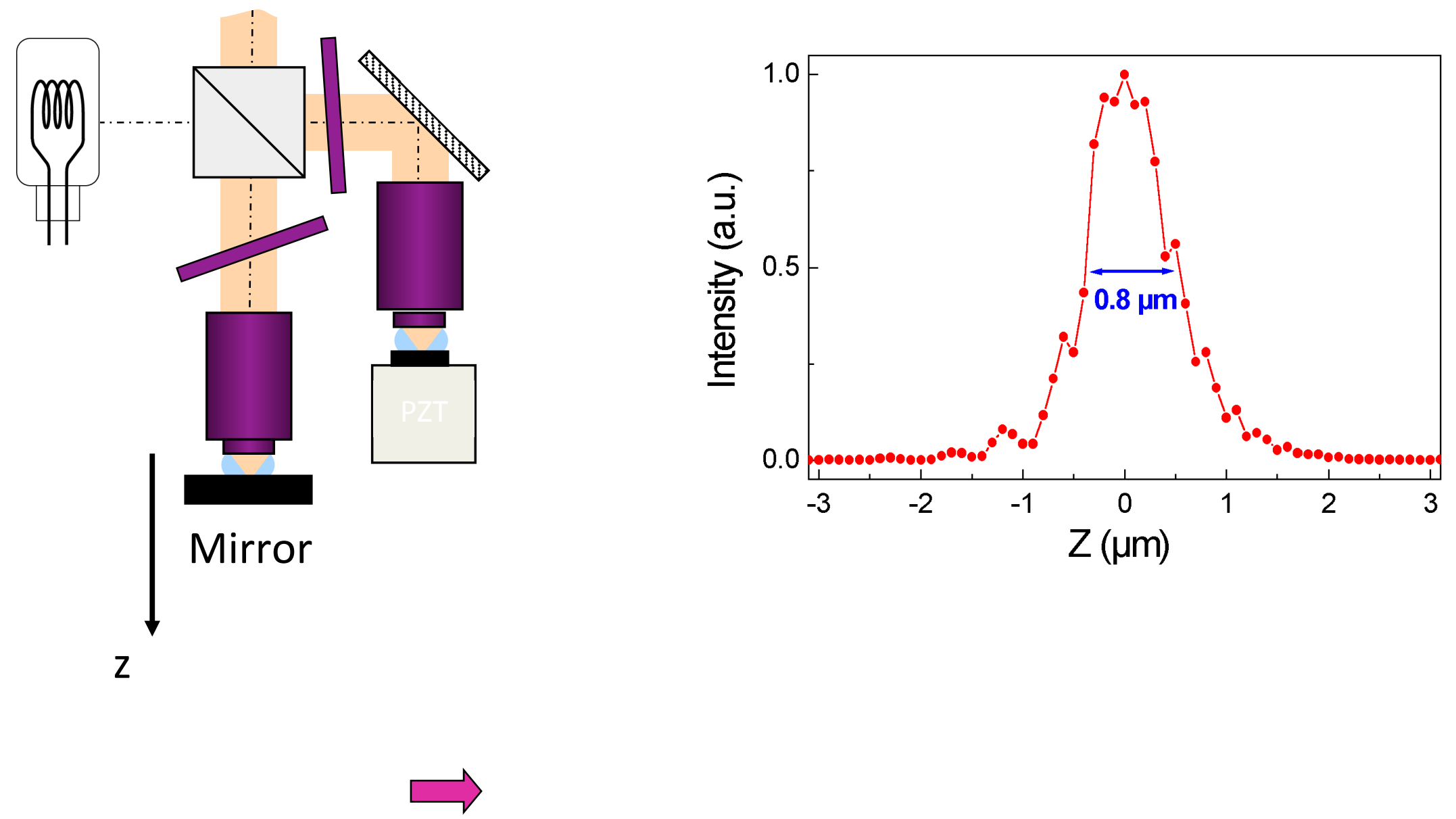


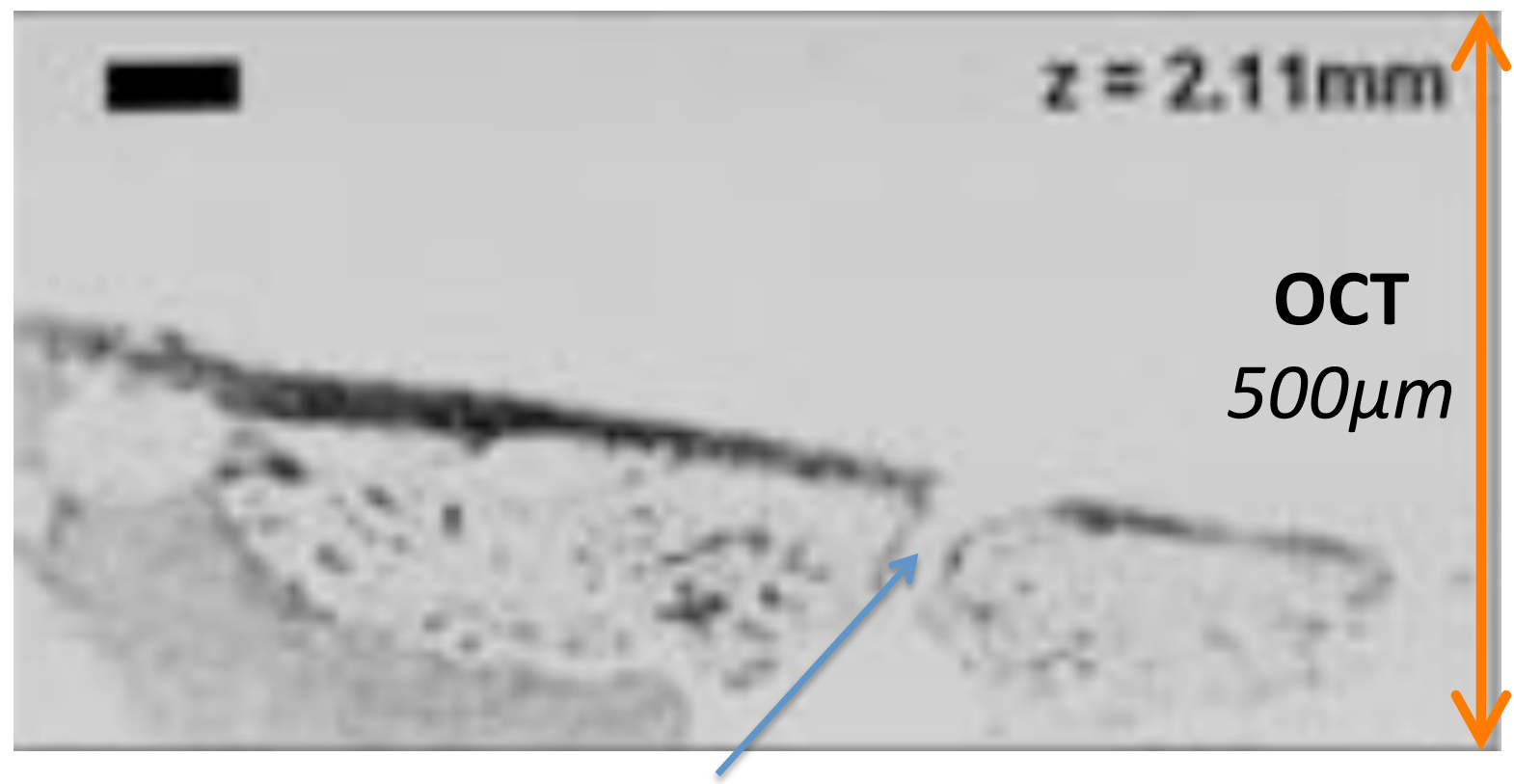

S. Boppart and col. Optical Biopsy of Lymph Node Morphology using Optical Coherence Tomography Technology in Cancer Research \& Treatment ISSN 1533-0346

Volume 4, Number 5, October (2005) CAdenine Press (2005)

Lymphatic channels

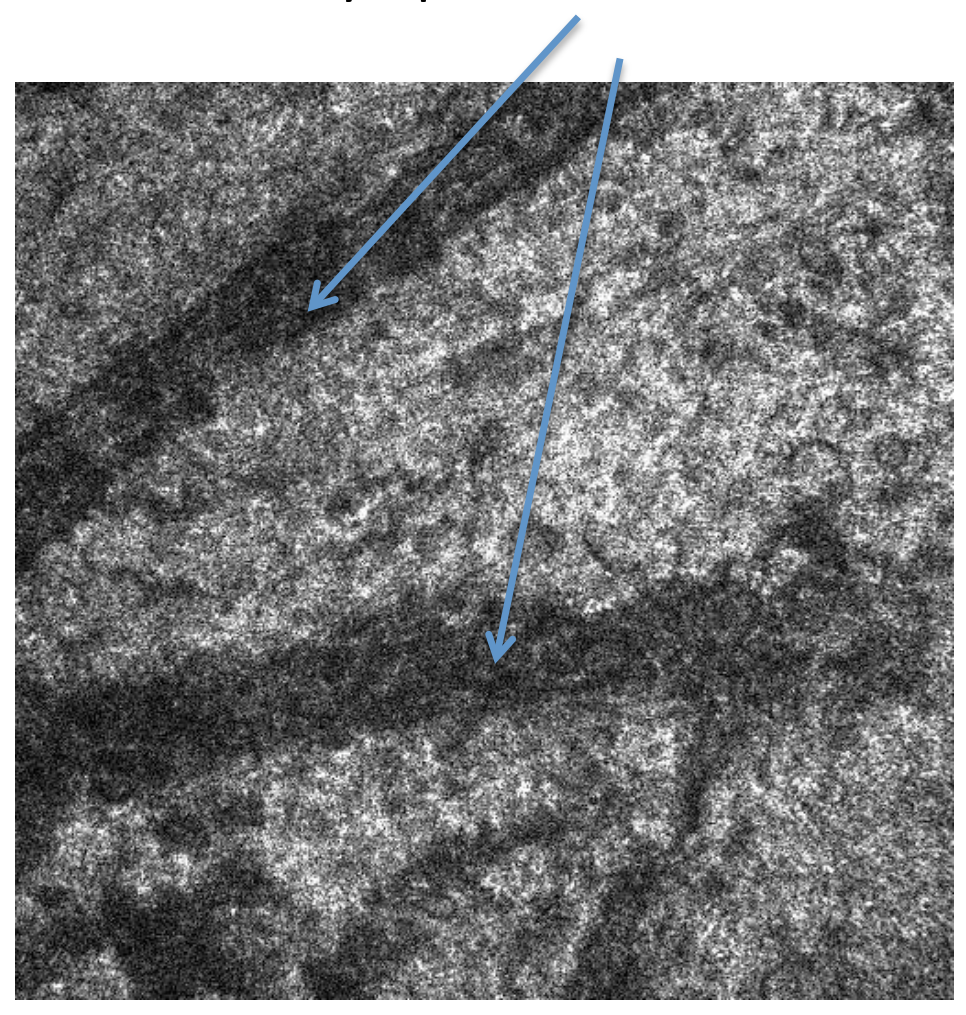

\section{Lymph Nodes}

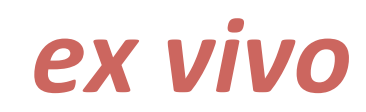

\section{FFOCT} 500 $\mu \mathrm{m}$ 
Benign and Malignant Lesions in the Human Breast Depicted with Ultrahigh Resolution and Three- dimensional Optical Coherence

\section{Tomography}

J. Fujimoto and col.

Radiology 2007; 244:865- 874

with dynamic refocusing

\section{FFOCT}

$500 \mu \mathrm{m}$

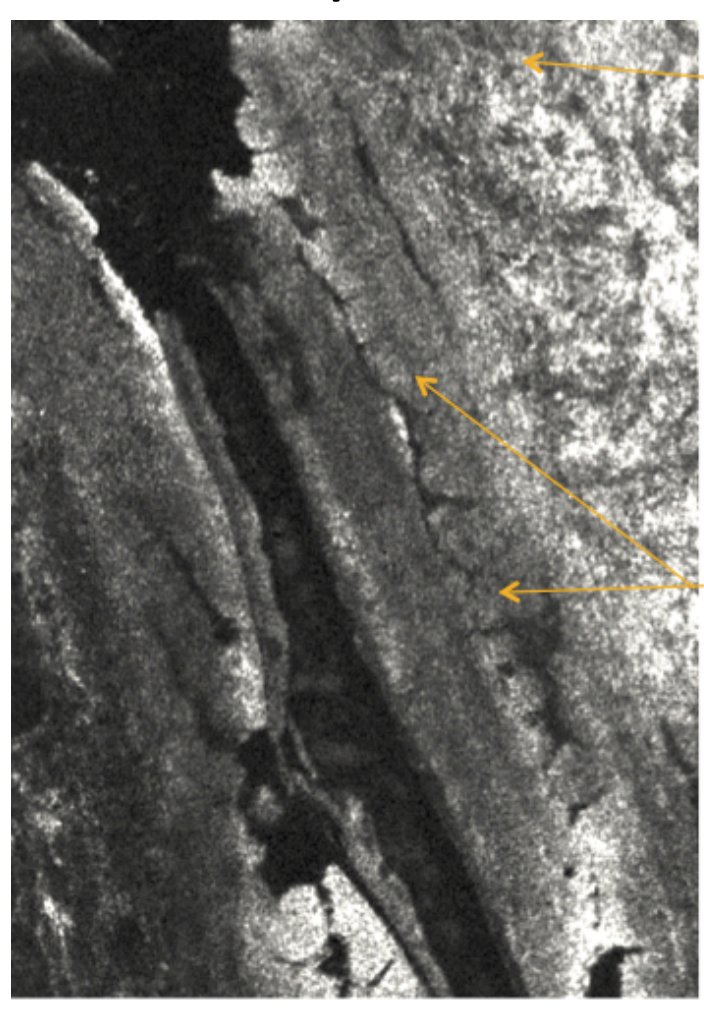

\section{MILK DUCTS}

Supporting tissue

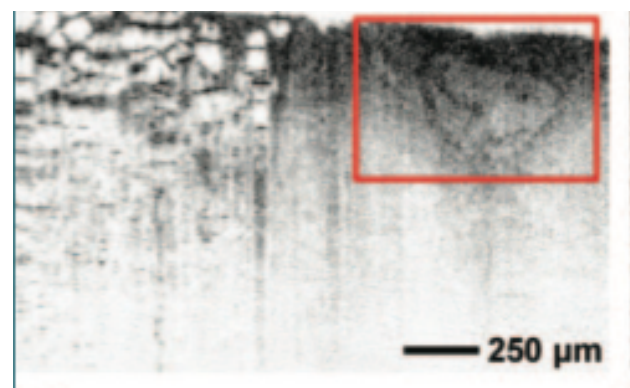

a.

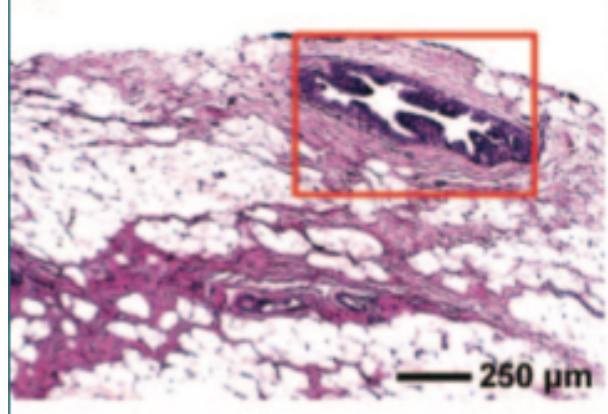

c.

Figure 6: (a, b) OCT images of ductal hyperplasia. On b, magnified image of ductal region in inset on a shows highly scattering projections into the ductal lumen corresponding to hyperplastic epithel lium or fibrovascular core (arrowheads). (c, d) Histologic specimens corresponding to OCT images. (Hematoxylin-eosin stain; original magnification, $\times 40$ in $c$ and $\times 100$ in $\mathrm{d}$.)

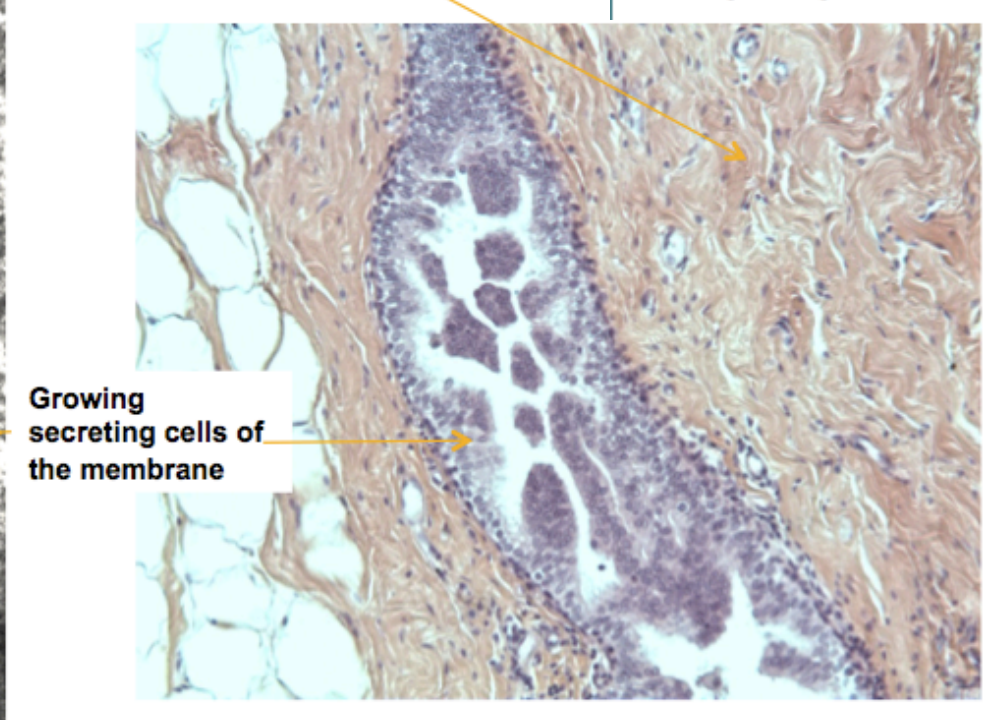




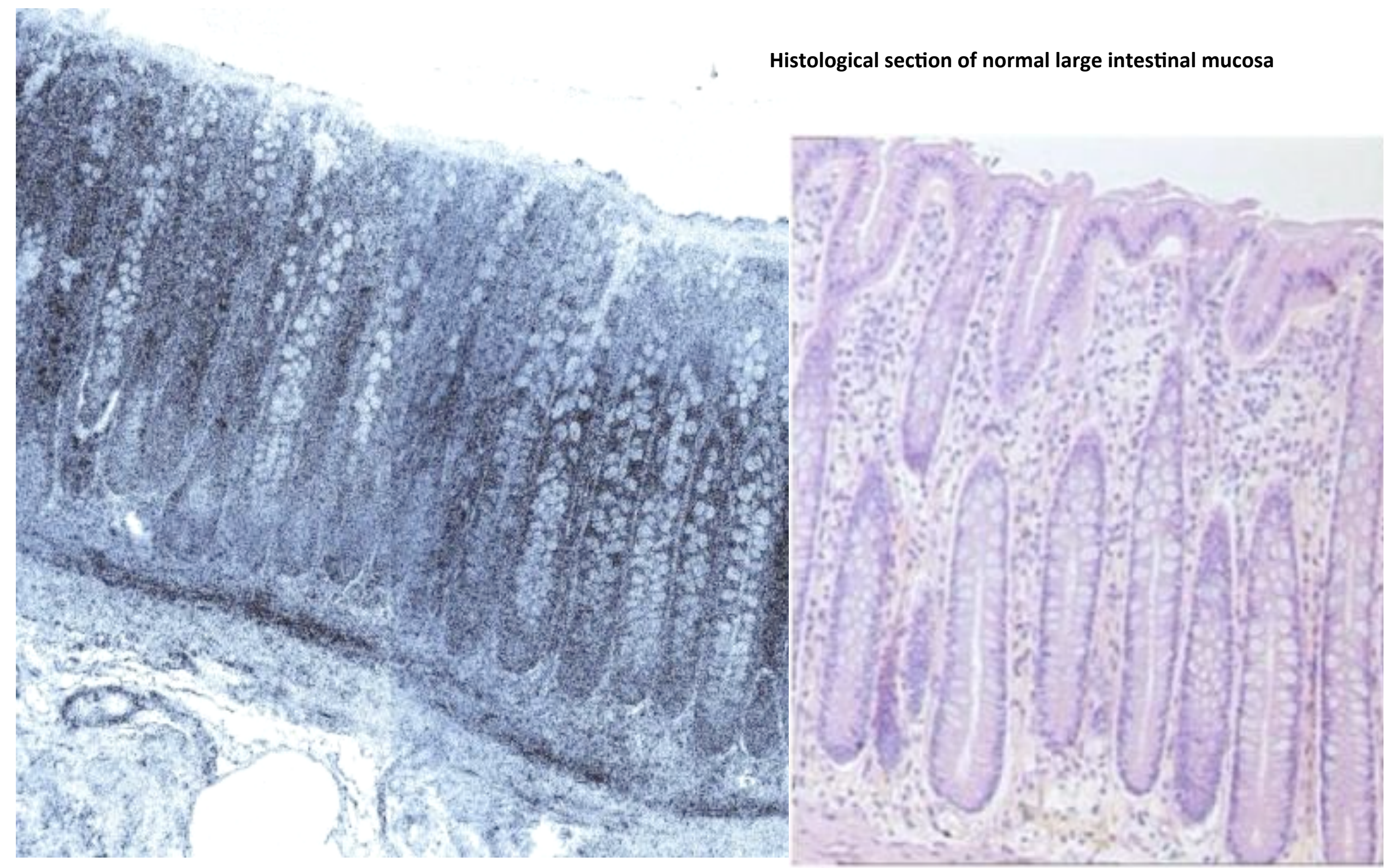

NORMAL COLON 


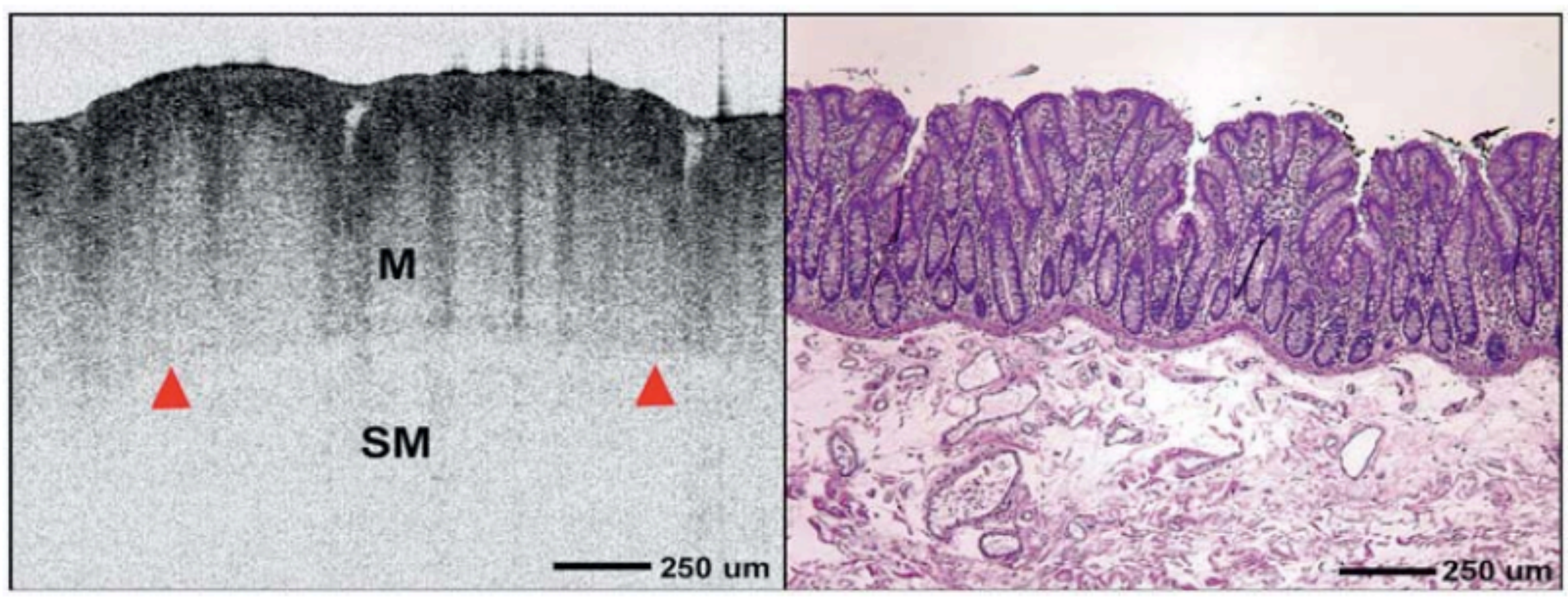

Figure 7.21 Ultrahigh-resolution OCT image of normal colon ex vivo (left) and comparison histology (right). Mucosa (M) is clearly delineated from underlying submucosa (SM) by a scattering band corresponding to the thin muscularis mucosa (arrowheads). The submucosa is visible as a less optically scattering layer. Images were acquired with $4.5-\mu \mathrm{m}$ axial and $11-\mu \mathrm{m}$ transverse resolution at a 1.26- $\mu \mathrm{m}$ wavelength (Hsiung et al., 2005).

\section{NORMAL COLON}




\section{FULL-FIELD OCT (FFOCT) : FROM BENCH TO THE OPERATING ROOM}




\section{Human colon - fixed tissue FFOCT results are comparable to traditional histology}

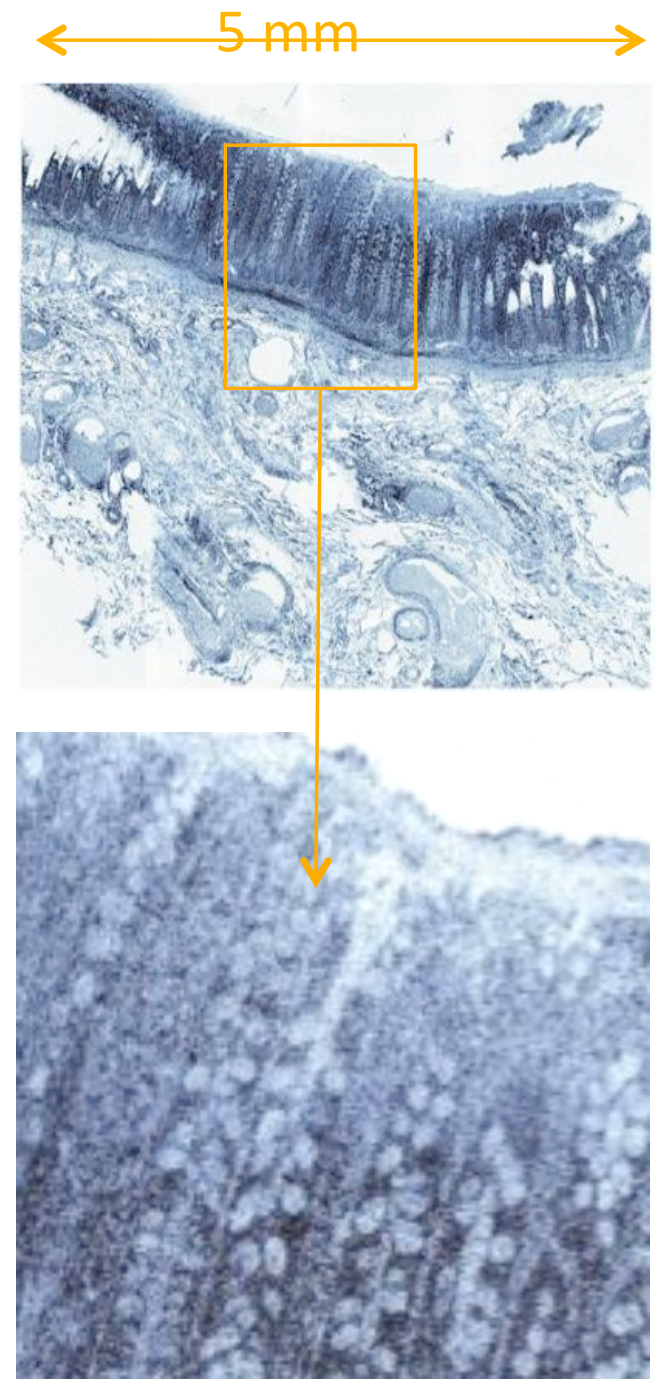

FF OCT

Few minutes

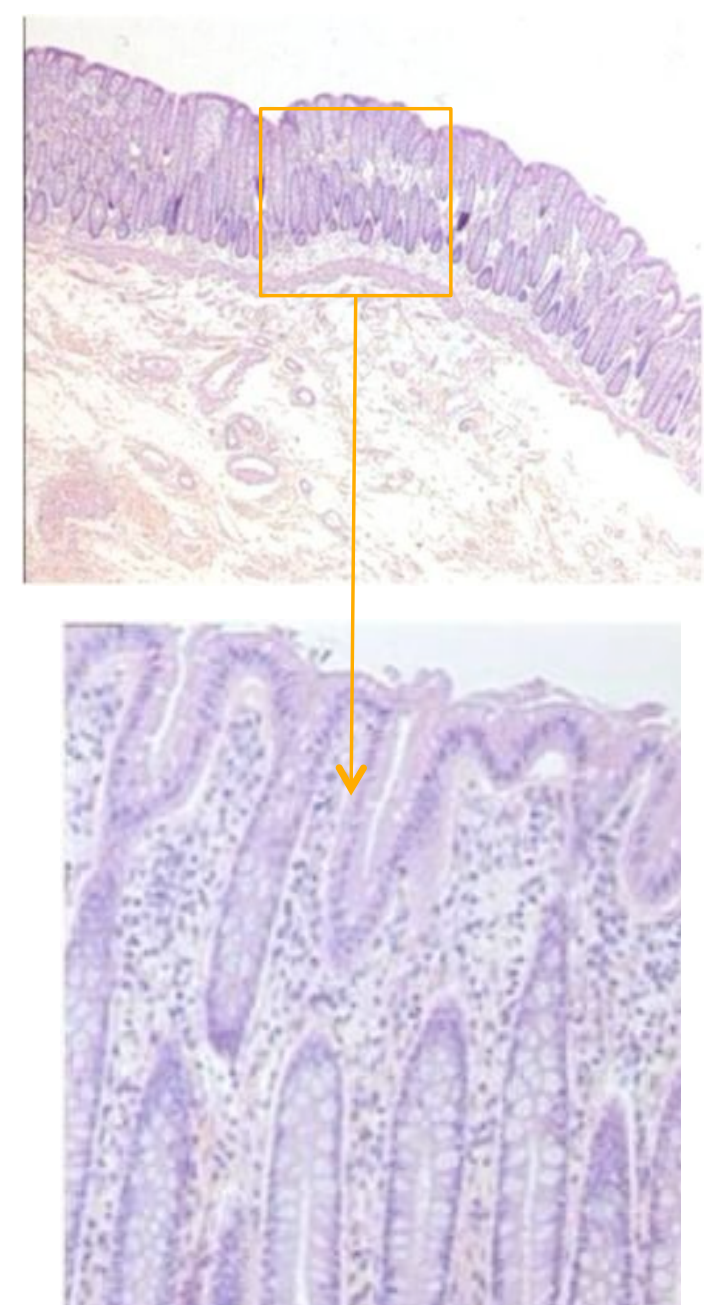

$\times 20$

$X 100$

Traditional histology Several days 


\section{Human colon - fixed tissue FFOCT results are comparable to traditional histology}
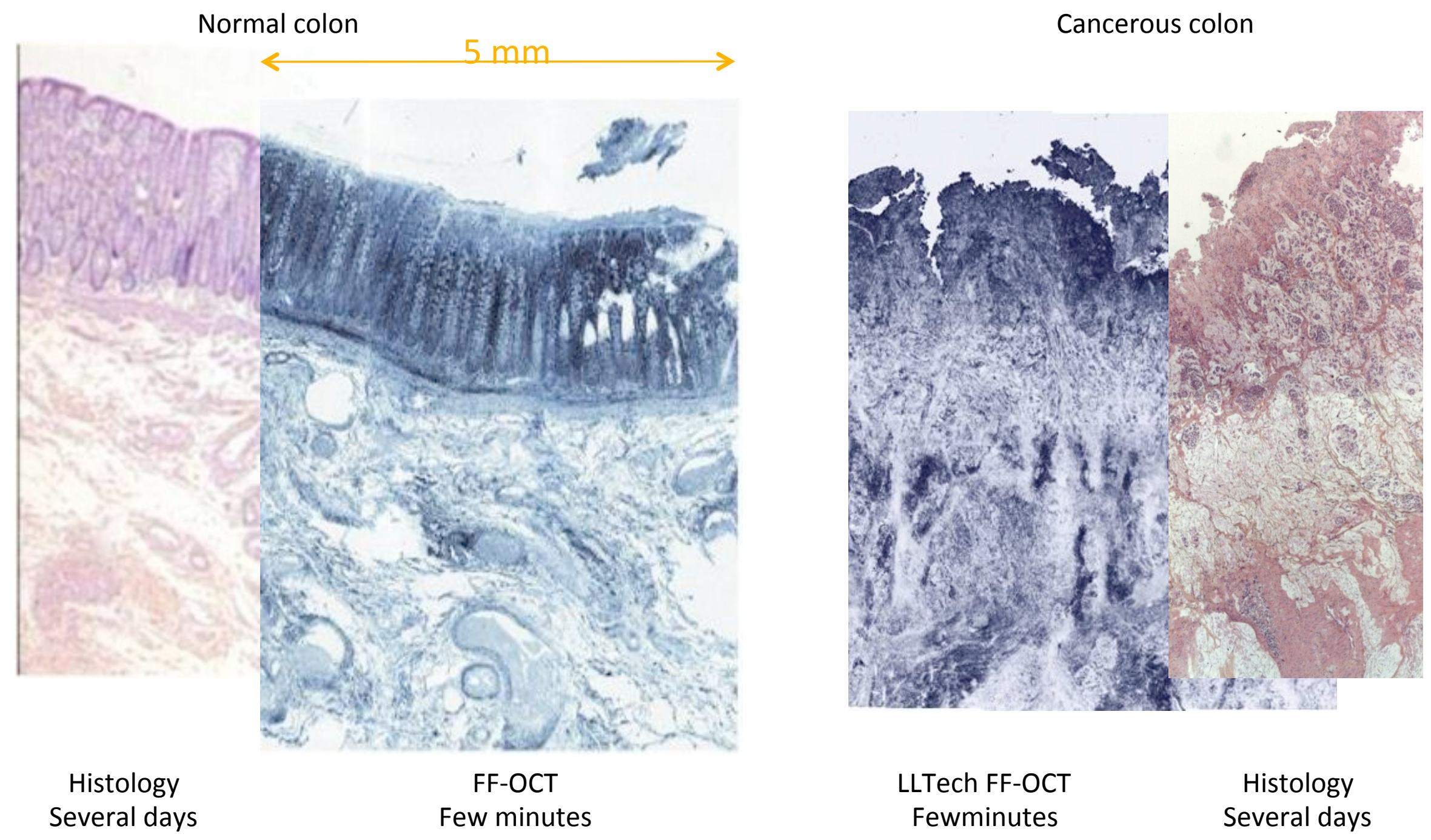


\section{ILEON 3D Imaging enable virtual navigation at a cellular level into the analyzed tissue}

$3 R$ rendering of human intestine

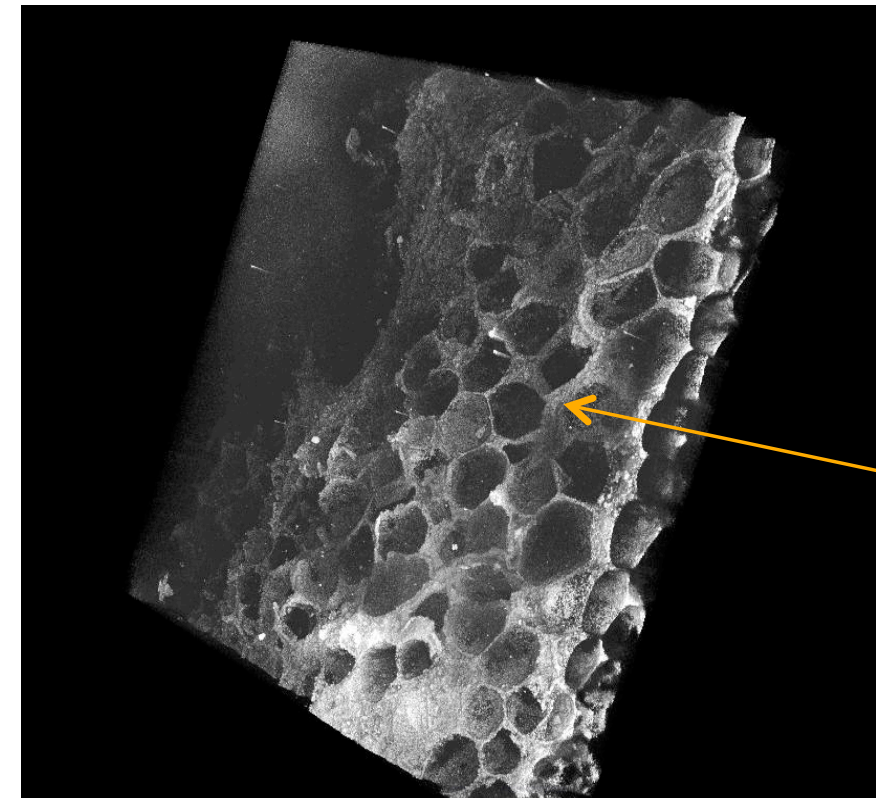

The 3D viewer allows to virtually navigate into the volume

Crohn's disease structure not visible at the surface

Fat cells

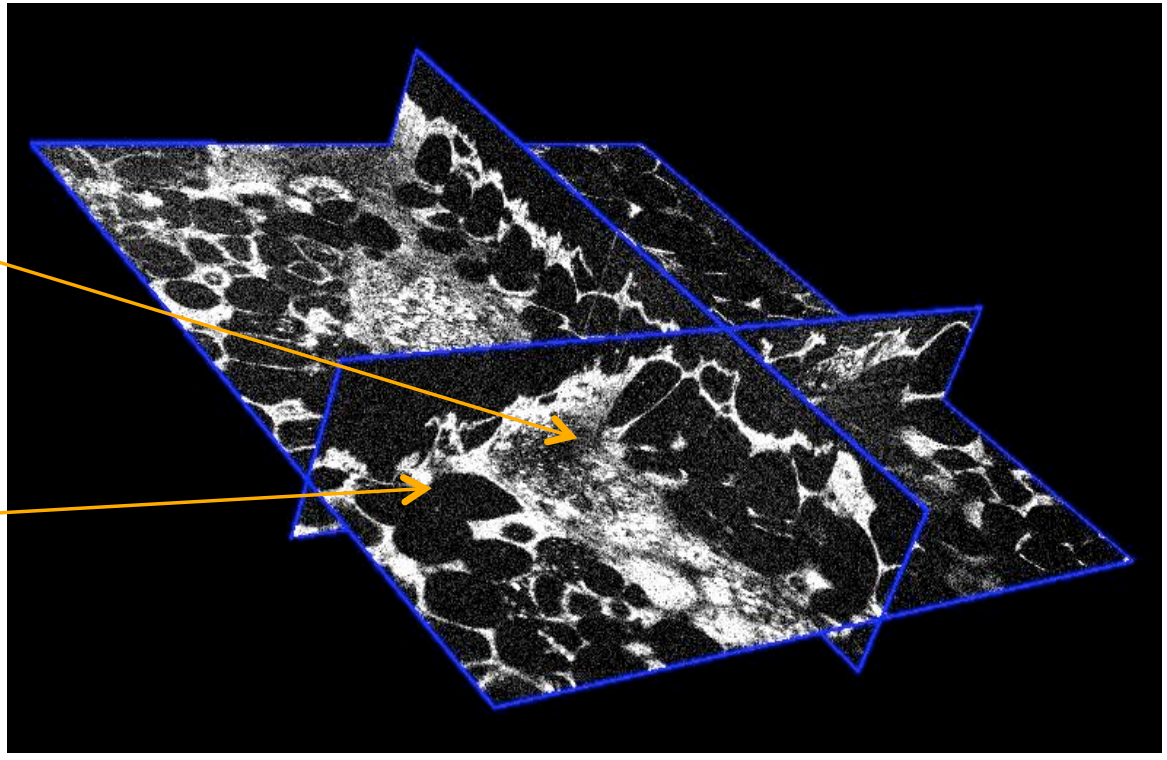


ILEON 3D Imaging enable virtual navigation at a cellular level into the analyzed tissue

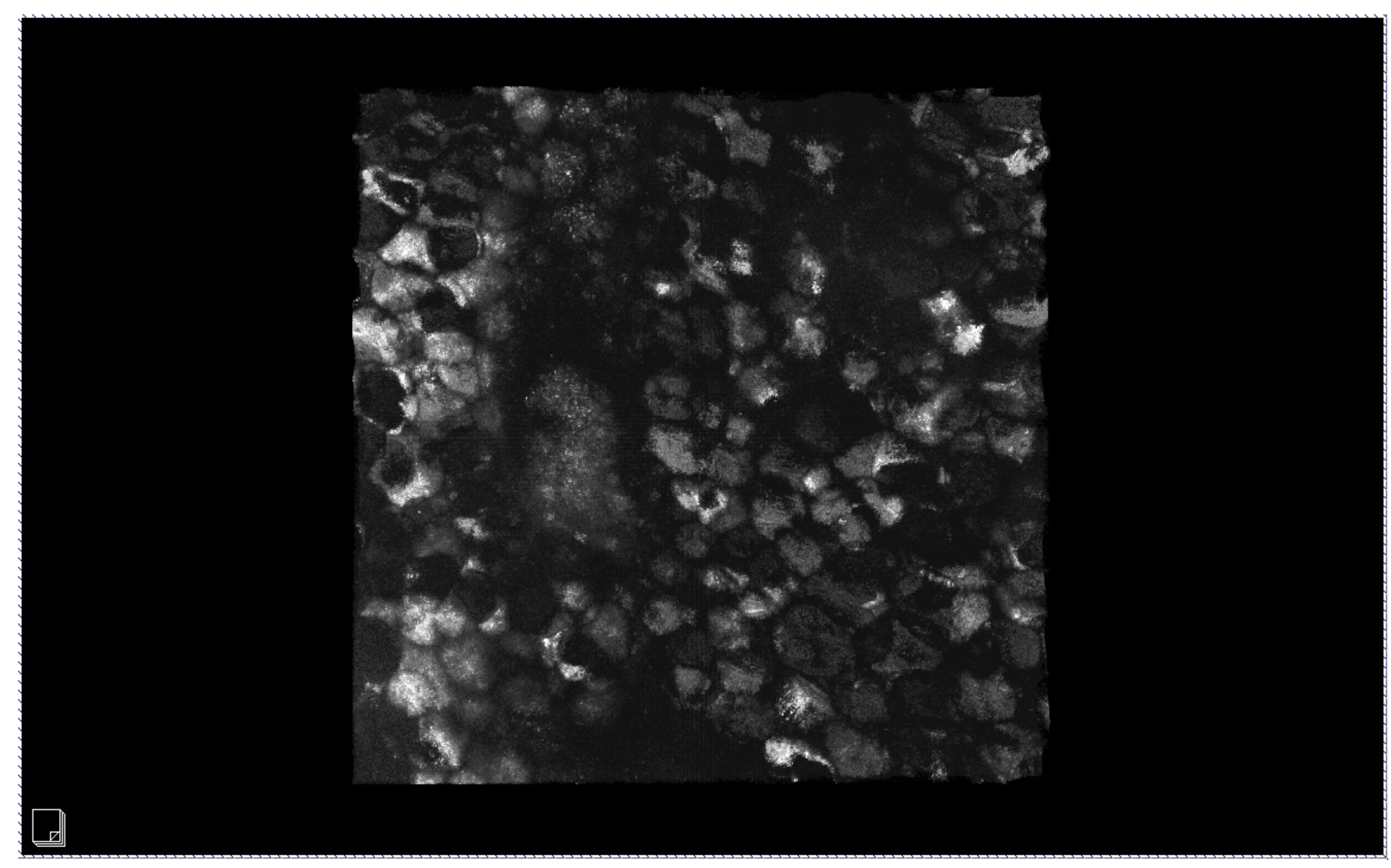




\section{Human colon - fixed tissue FFOCT Zoom on chosen parts}
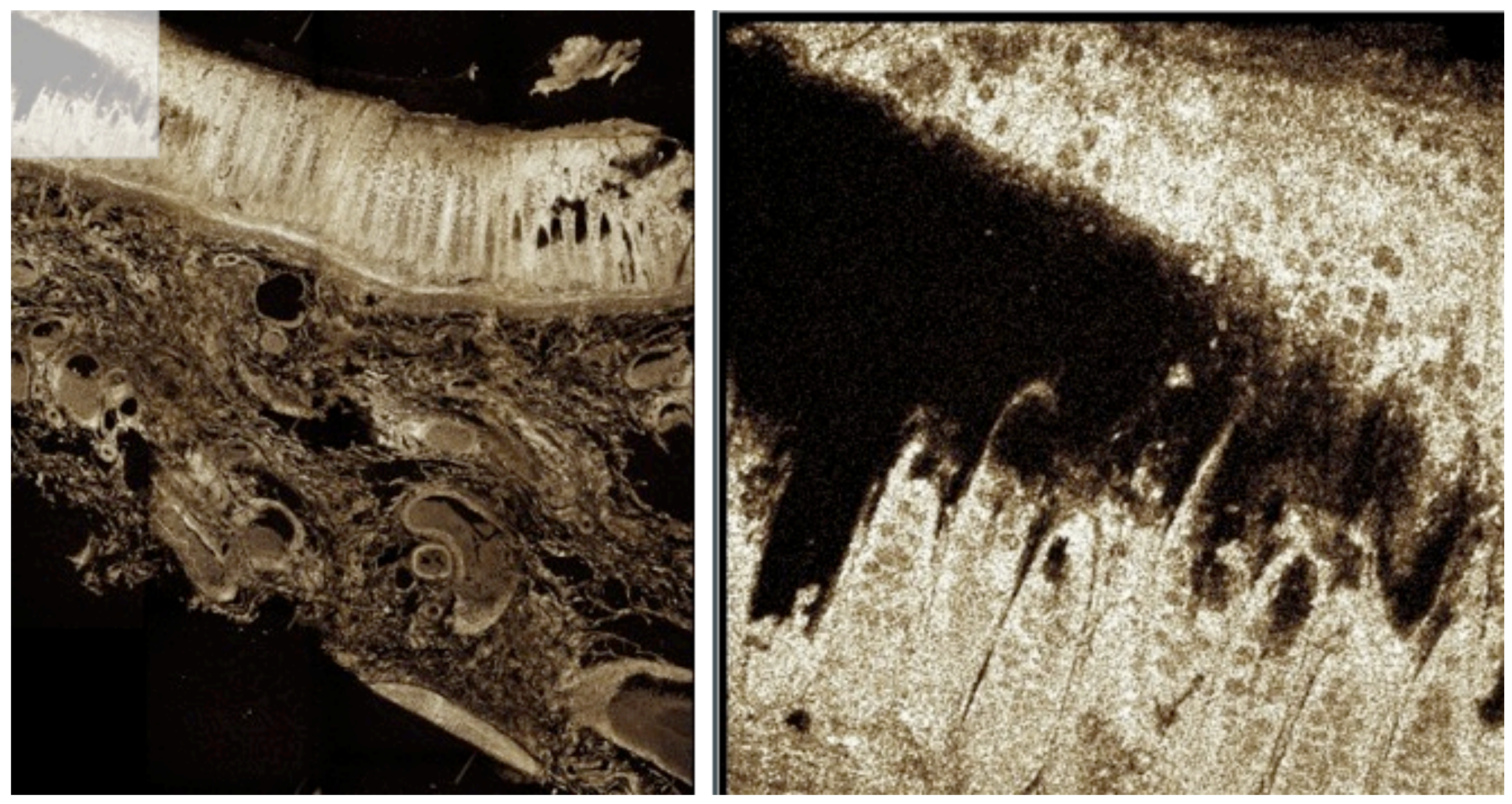


\section{BREAST CANCER SURGERY \\ FFOCT PICTURES ARE COMPARABLE TO HISTOLOGY}

$10 \mathrm{~mm}$

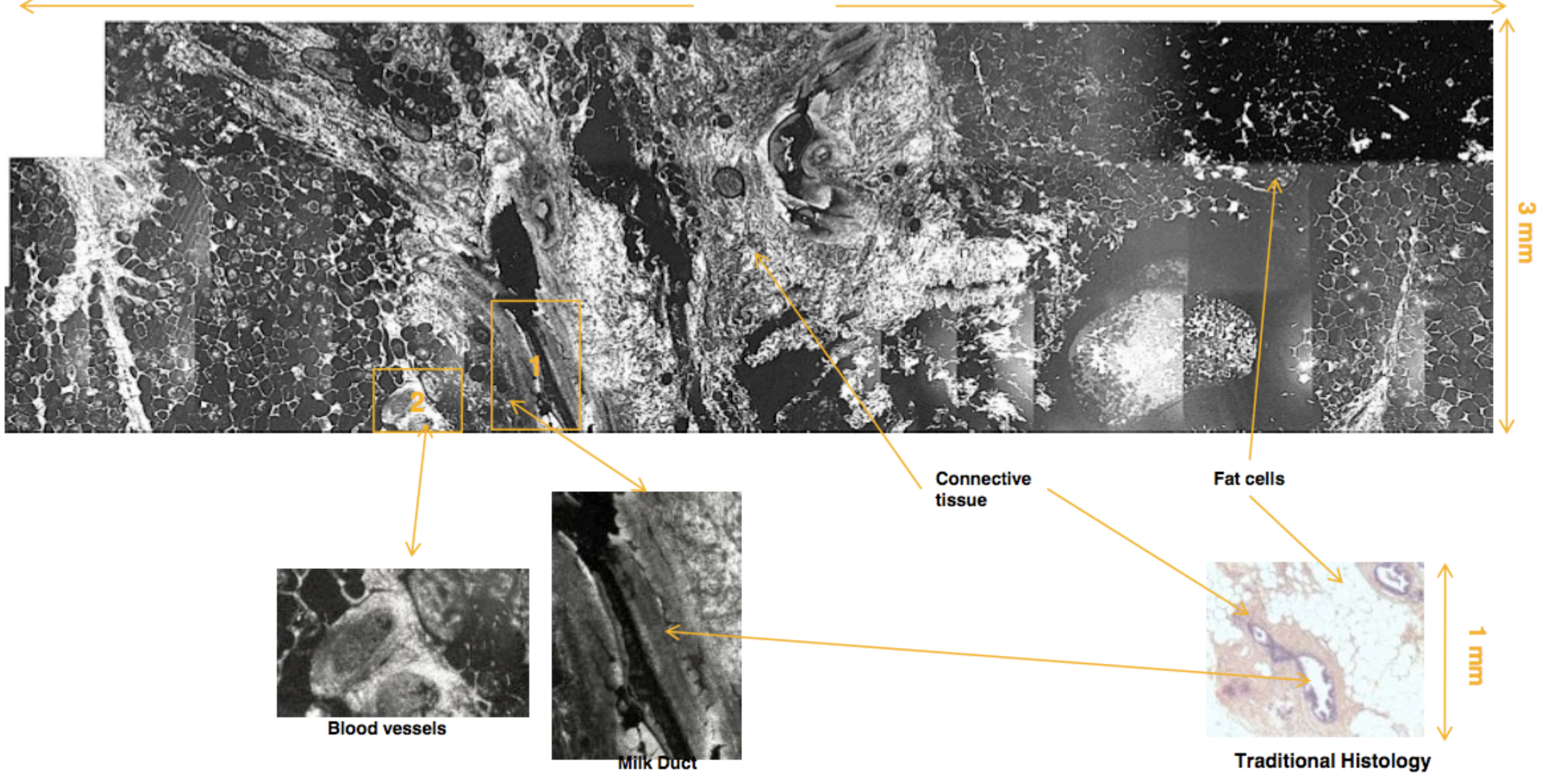




\section{Breast Histology Identification of the milk duct structures}

$8 \mathrm{~mm}$
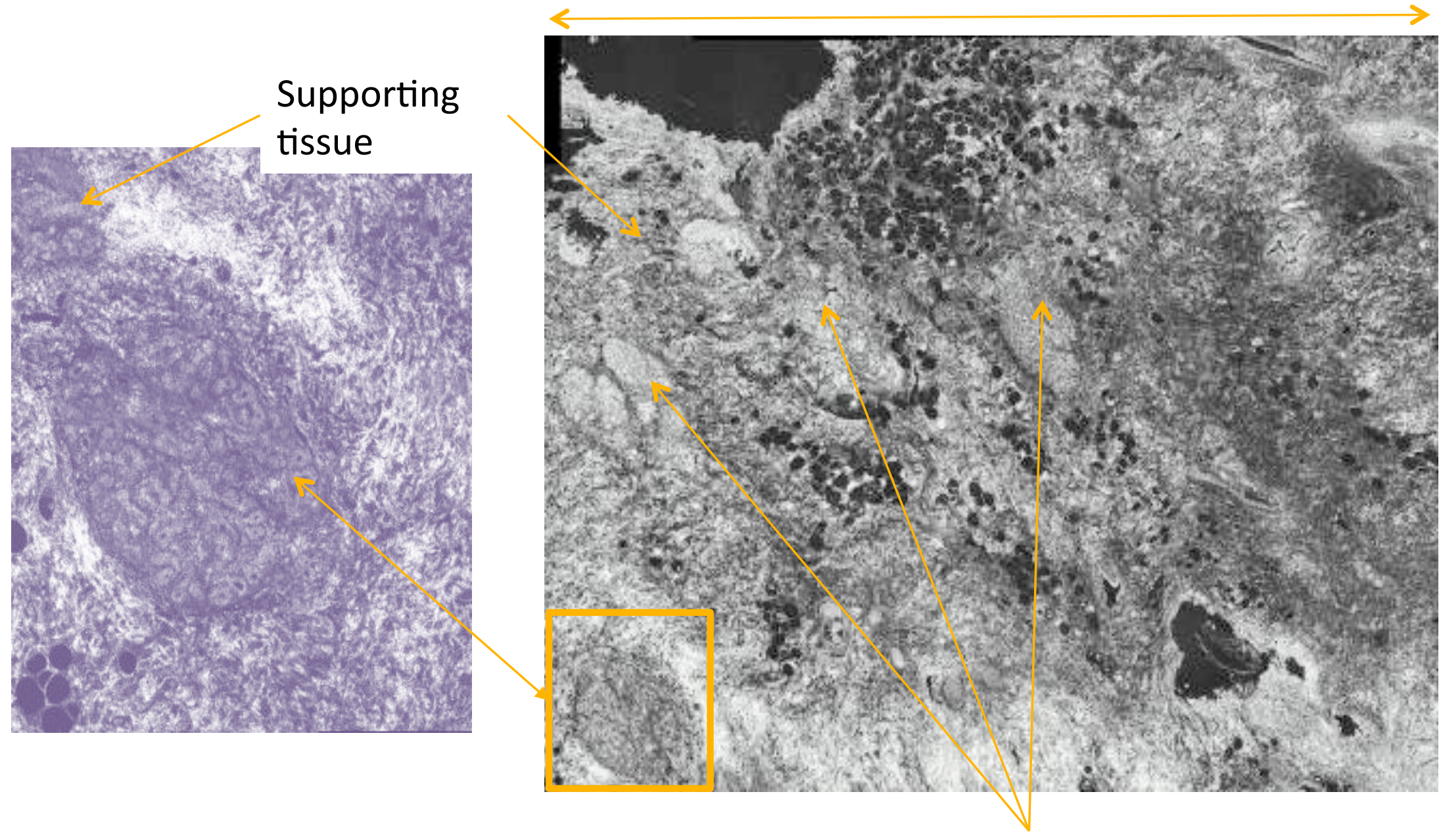

Milk duct structures 


\section{Breast cancer surgery Milk Duct Structures}
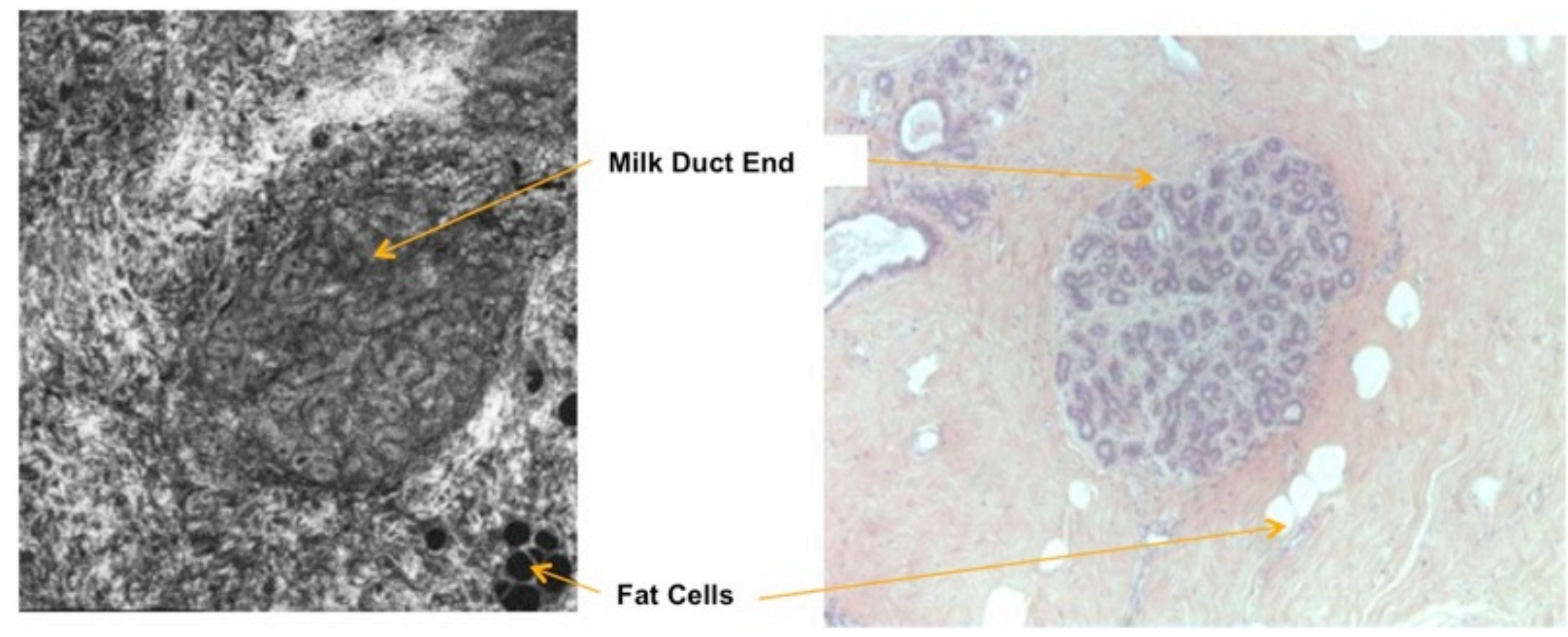


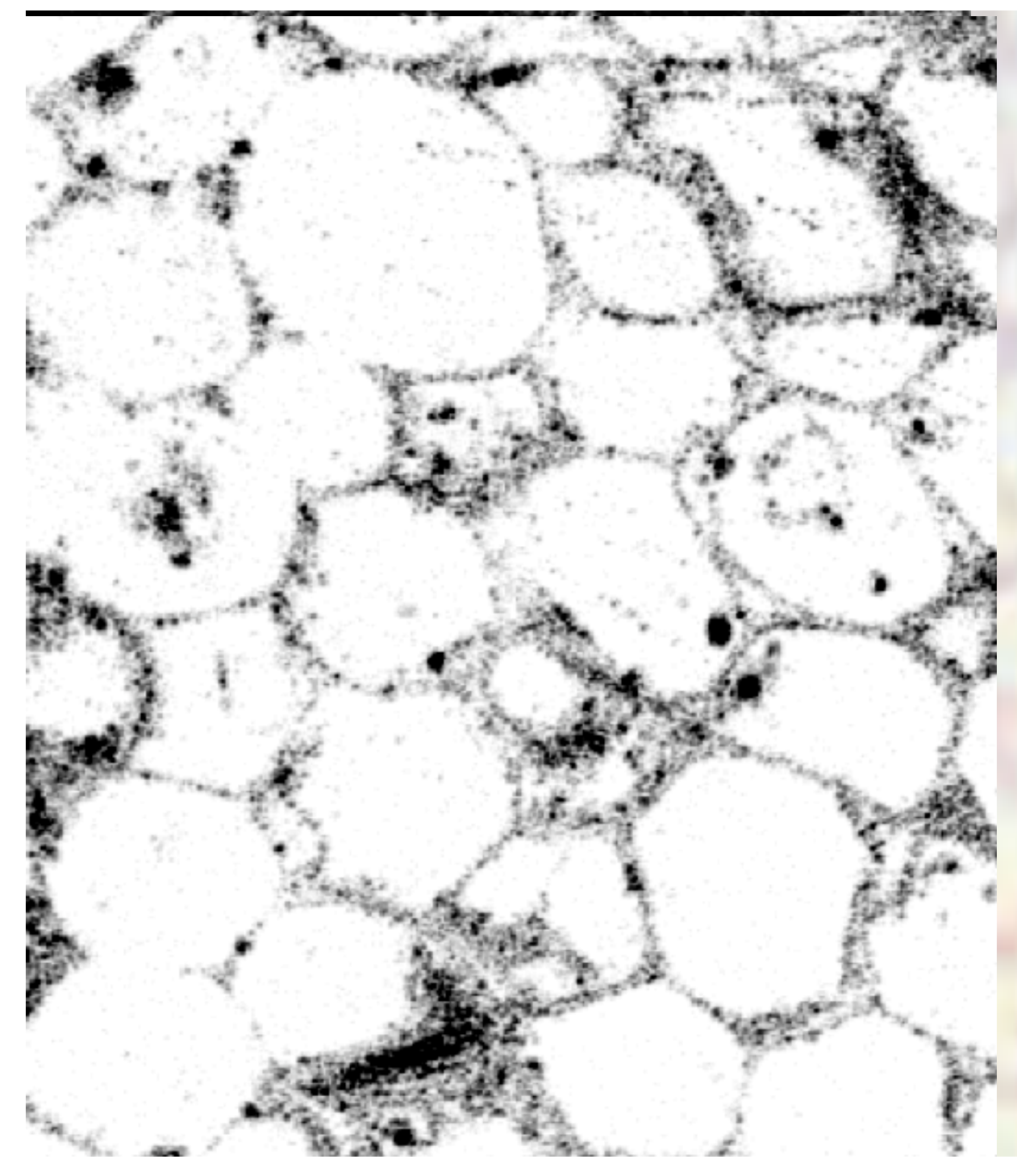

Light-CT (10x 0.3NA)

Histology 


\section{ANIMAL MODEL: IN VIVO IMAGING OF RATS BRAIN}




\begin{tabular}{|c|}
\hline Rat brain \\
Objective:40x \\
Field of view \\
$120 \times 120 \mu \mathrm{m}^{2}$ and $260 \times 260 \mu \mathrm{m}^{2}$ \\
Col. L.Bourdieu's group ENS \\
\hline
\end{tabular}
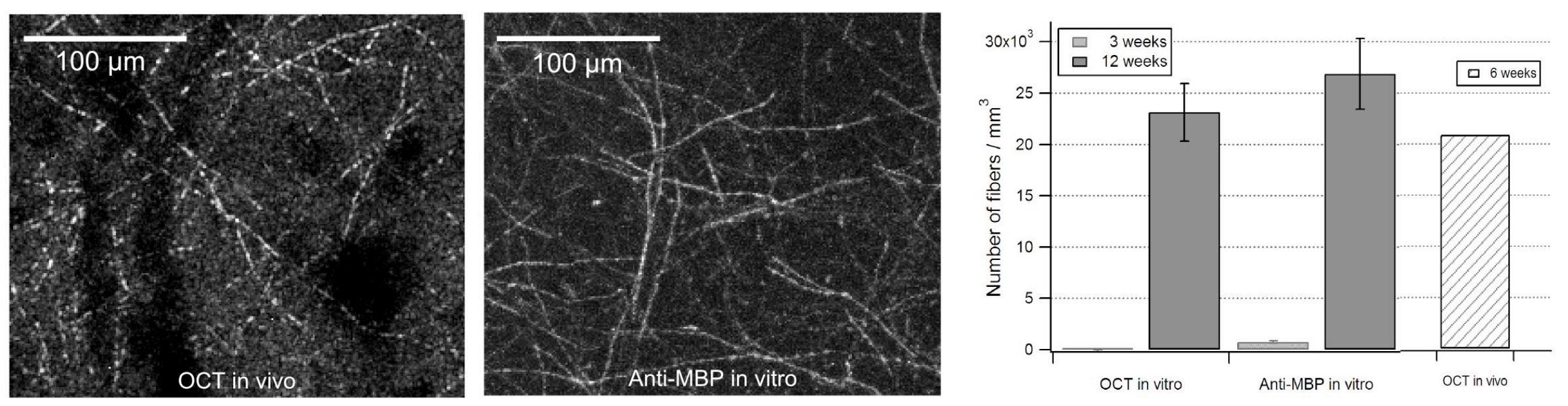

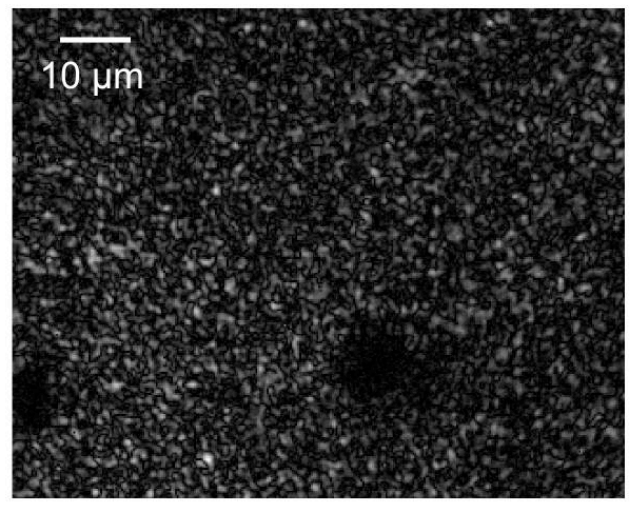

3 weeks

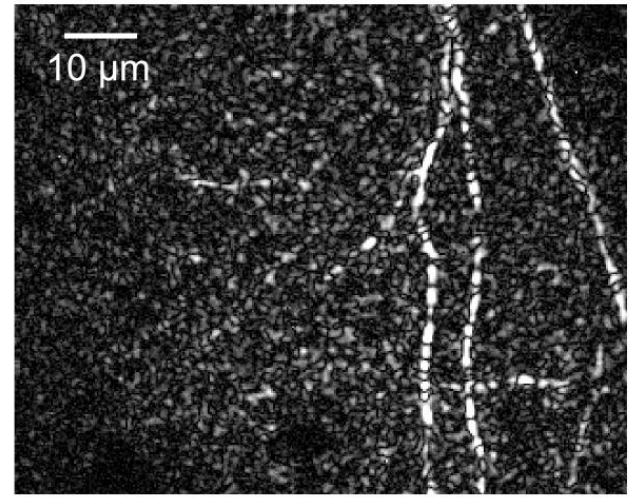

6 weeks

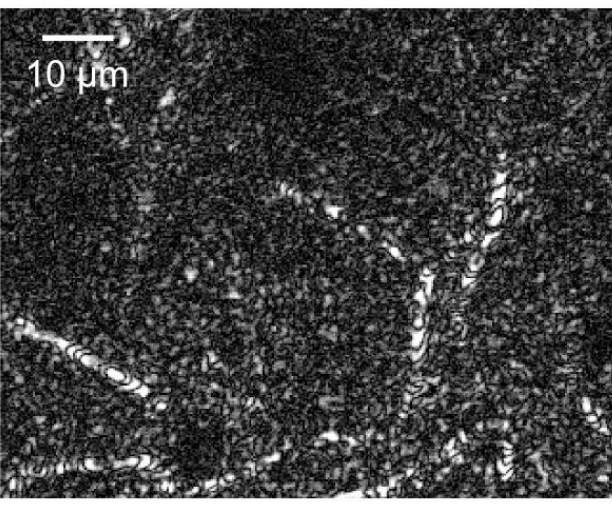

12 weeks

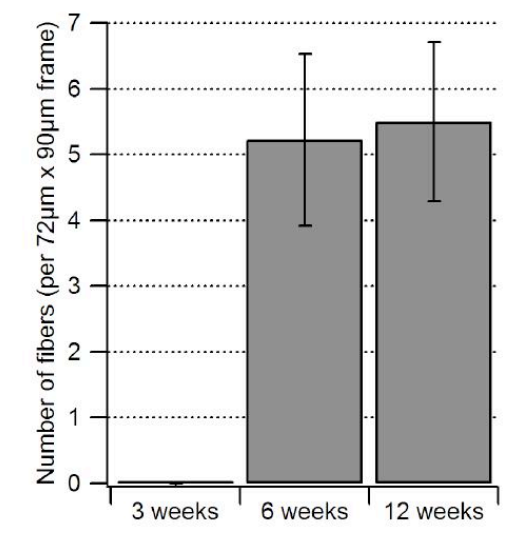




\section{RAT BRAIN: BLOOD CIRCULATION}

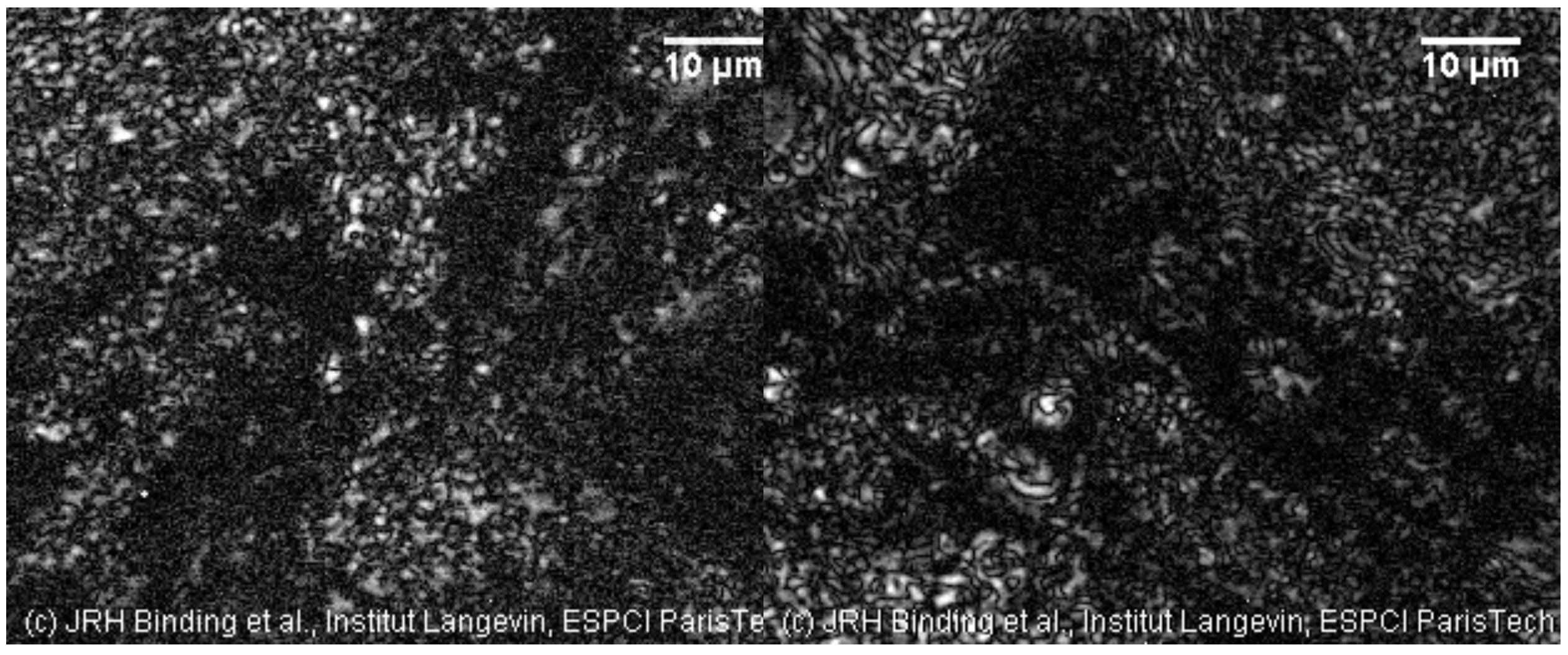




\section{TWO IMAGING APPROACHES}

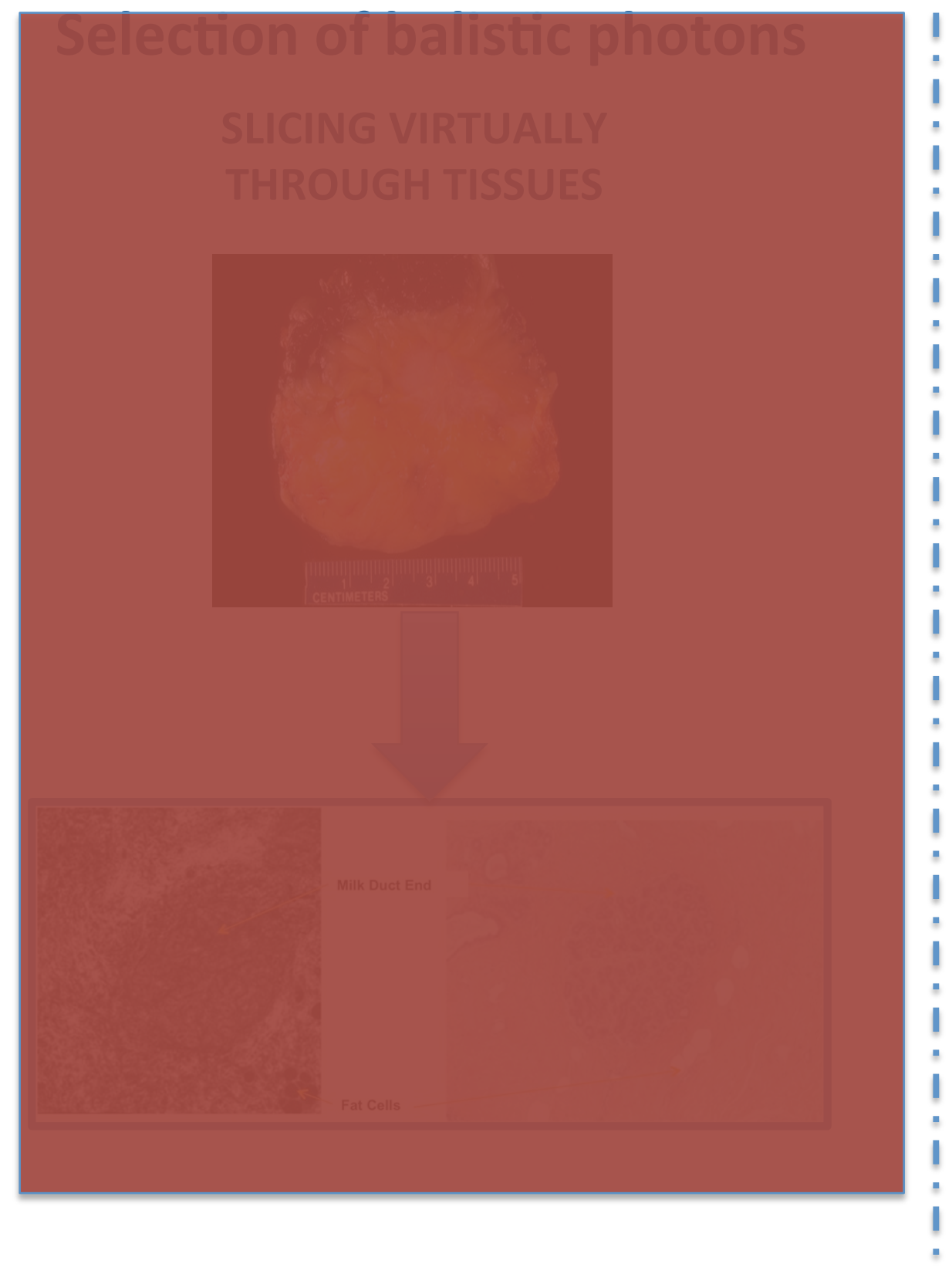

No more balistic light: seeing through an opaque wall
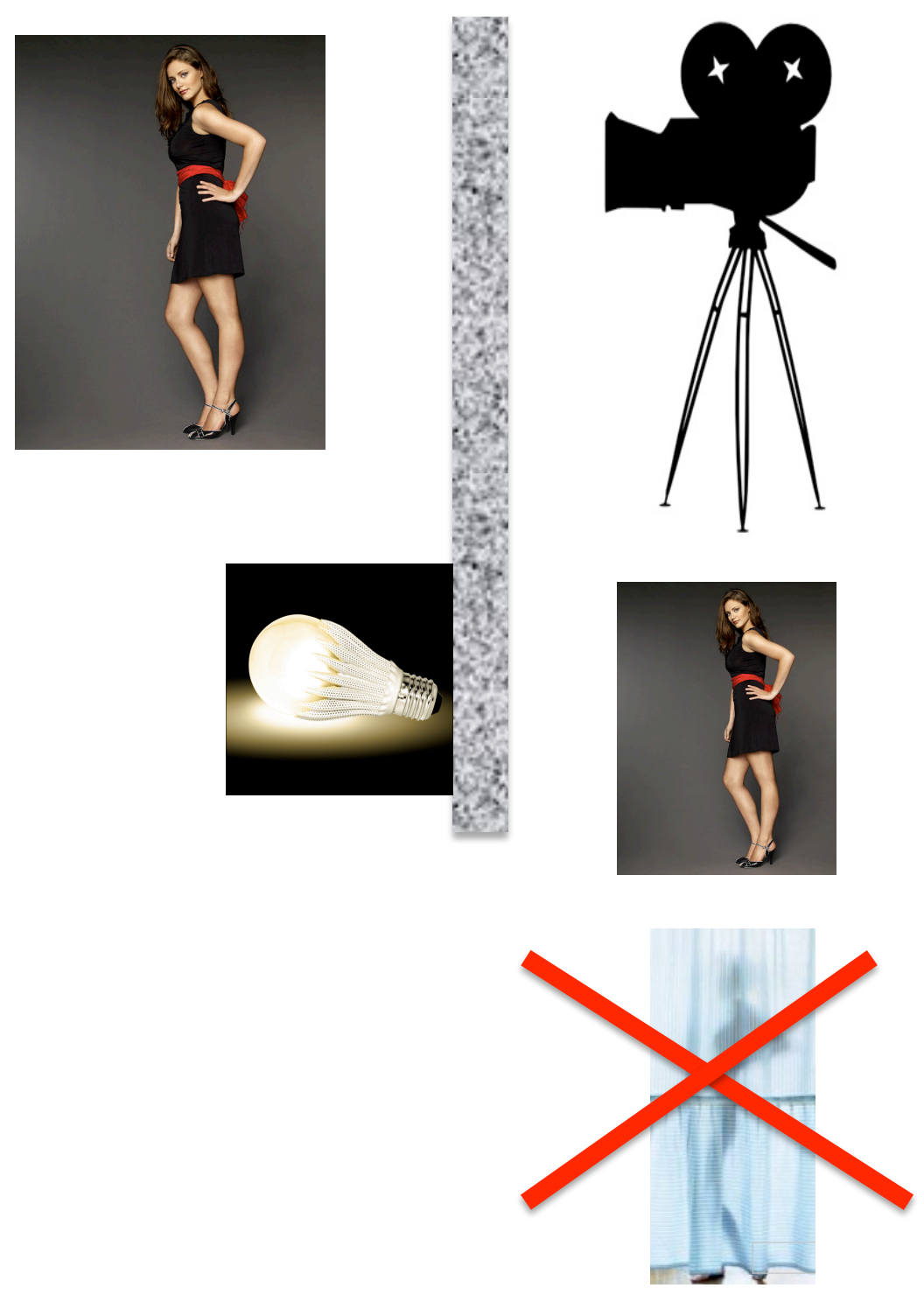


\section{An inspiring experiment !}

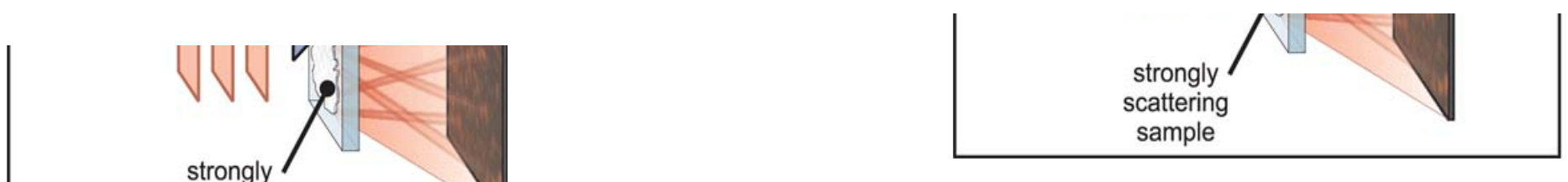

Fig. 1. (Color online) Design Fig. 1. (Color online) D wave is focused on a disı tern is transmitted. (b) is shaped so that scatte: vave is focused on a disorder tern is transmitted. (b) The $\mathrm{r}$ is shaped so that scattering $\mathrm{r}$ defined target.

defined taroot. 


\section{How does it works?}

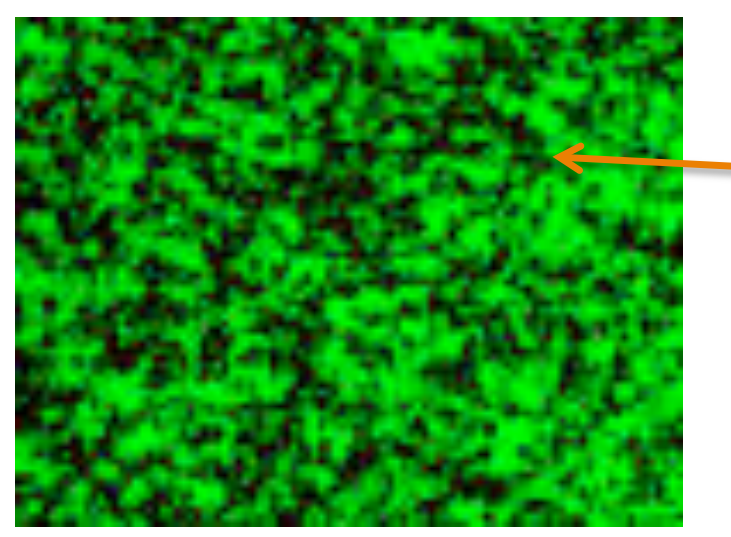

One speckle spot :

-Interference from many different path with random phases

-All input modes contribute!

- It is possible to put these modes in phase to obtain constructive interference

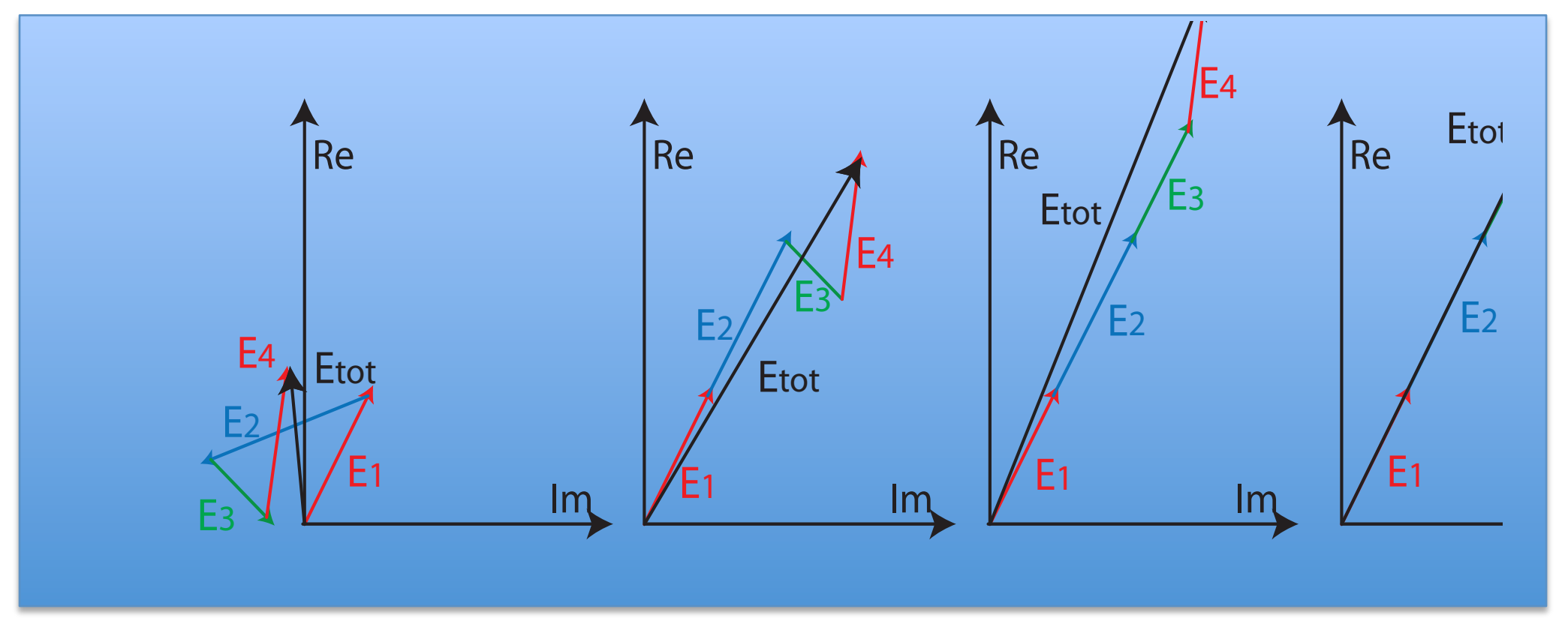




\section{Wavefront control device}

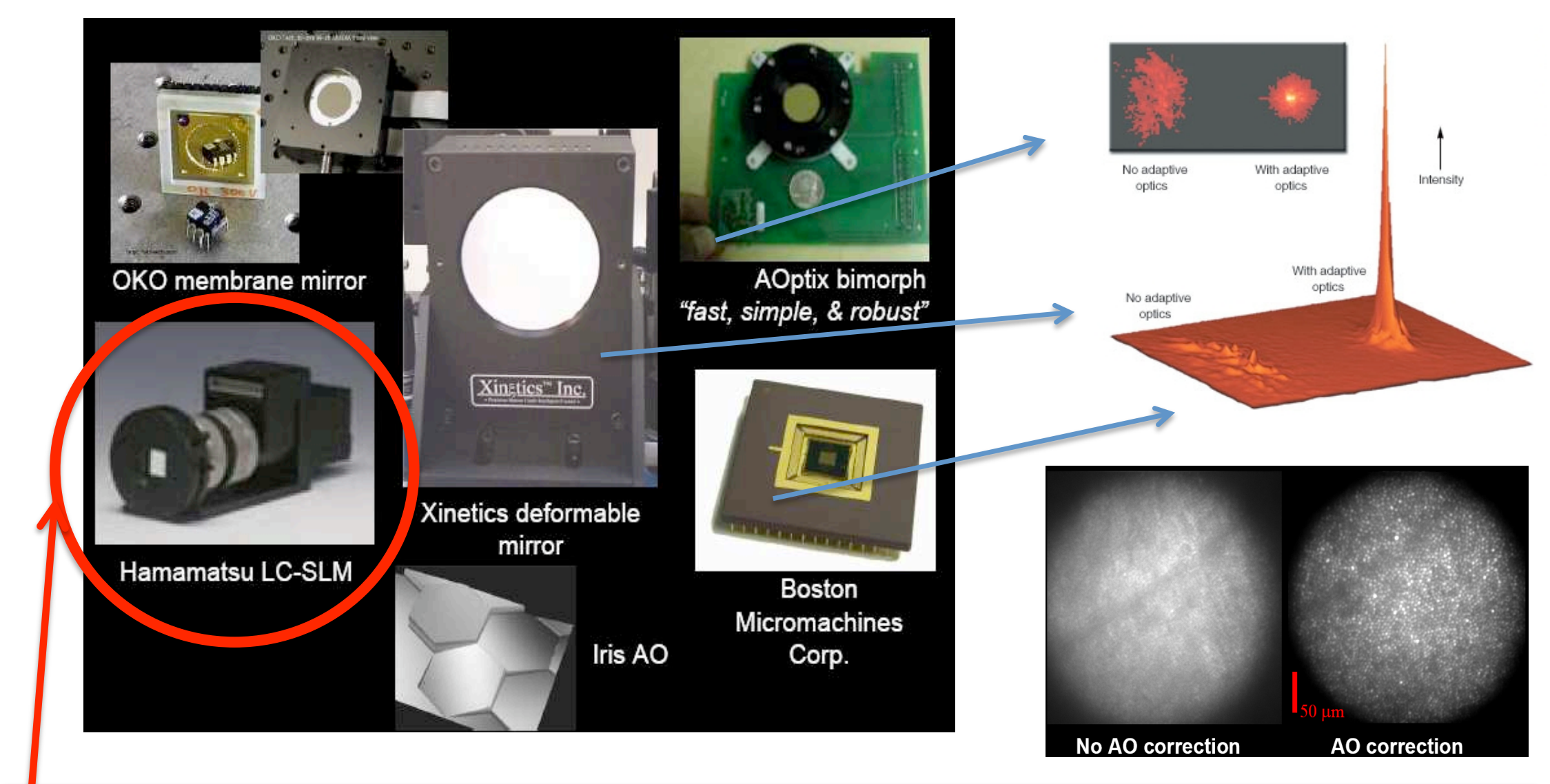

Deformable mirrors : $10-100$ actuators typical - course : 10-20 microns $-\mathrm{kHz}$ Spatial Light Modulators : 1 million pixel typical - course : 1 microns typical $-50 \mathrm{~Hz}$

Complex material $=\mathrm{a}$ LOT of degrees of freedom

SLM is (so far) more adapted 


\section{The scattering matrix}

Our system of study: $\mathrm{A}$ thick (opaque) layer of $\mathrm{ZnO}$ on a slab

-Very stable (stationary diffuser, stable speckle figure)

-Completely disordered, in the multiple scattering regime

-Linear, open system

A natural formalism: the scattering matrix

Link the input to the output fields of the system

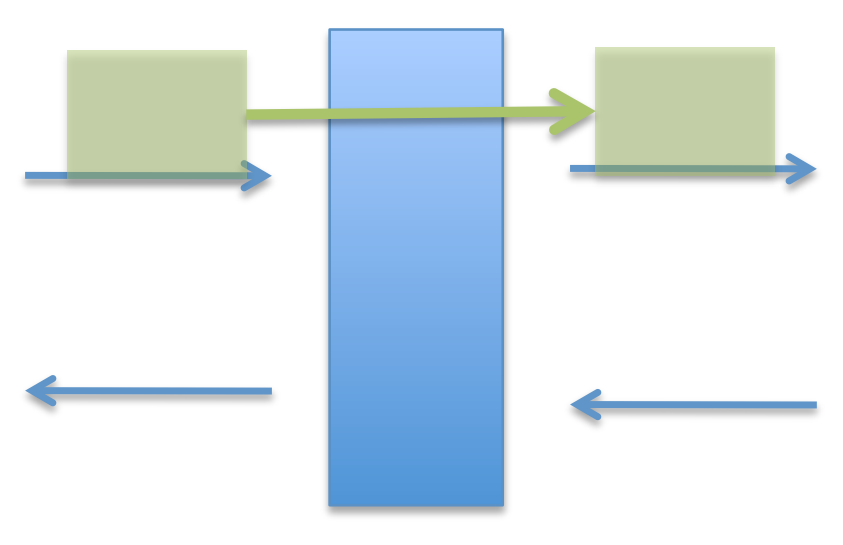

\section{Scattering matrix $\mathrm{S}$}

The transmission matrix (TM)

can be measured with a CCD and a SLM! 


\section{Experimental setup somple $_{\text {s. }}$}

$\mathrm{N}=256$

macropixels/

modes

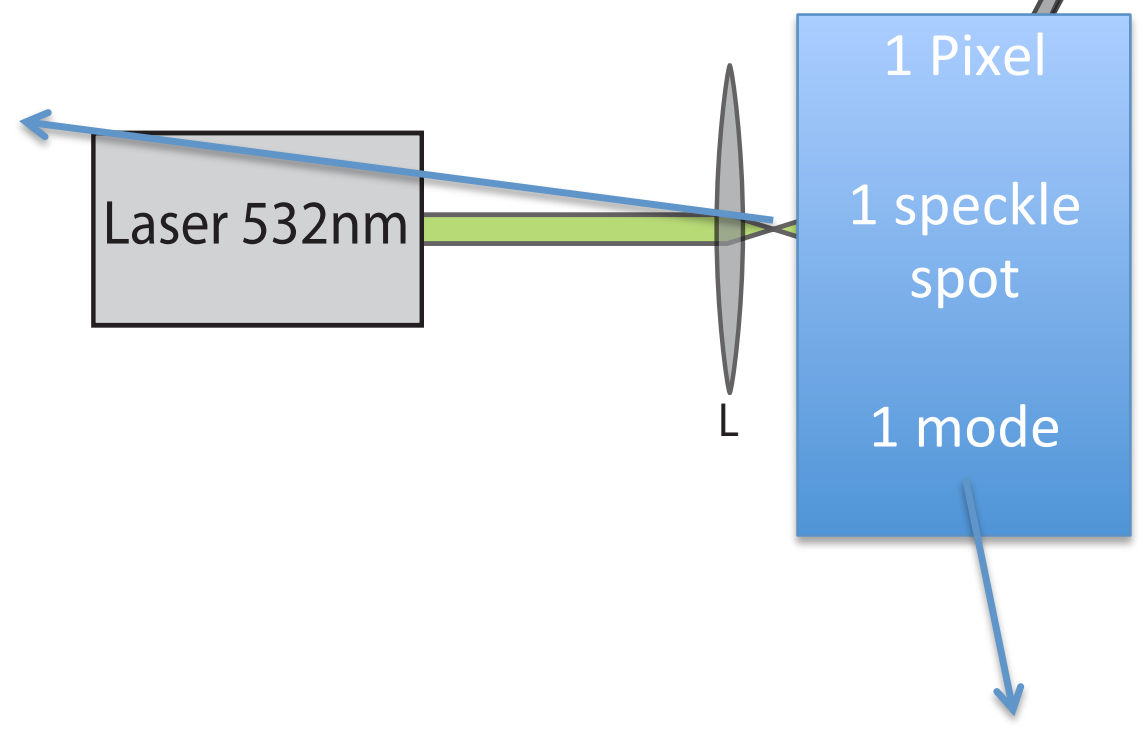

SLM

$\mathrm{N}=256$

macropixels

Iterative focusing in a time N (Allard Mosk Group)

/modes

We have been able to measure the transmission matrix $\mathrm{K}$ in $4 \mathrm{~N}$ steps

H

S. Popoff et al, Phys. Rev. Lett. 104, 100601 (2010) 


\section{Limitations}

-The TM measurements takes a lot of steps $\left(4 \mathrm{~N}_{\text {input }}\right)$

- Current limitation is the refresh rate of the $\operatorname{SLM}(50 \mathrm{~Hz})$, $\mathrm{N}_{\text {output }}$ on the CCD is not a limitation.

- Measuring the TM takes approx. 2-3 minutes for 256 pixels

-The TM can be used as long as the medium is stable (speckle stationnary). Paint : $>1$ hour, biological sample : $<1 \mathrm{~ms}$ !!! 


\section{Exploiting $\mathrm{K}_{\mathrm{obs}}$ : focusing}
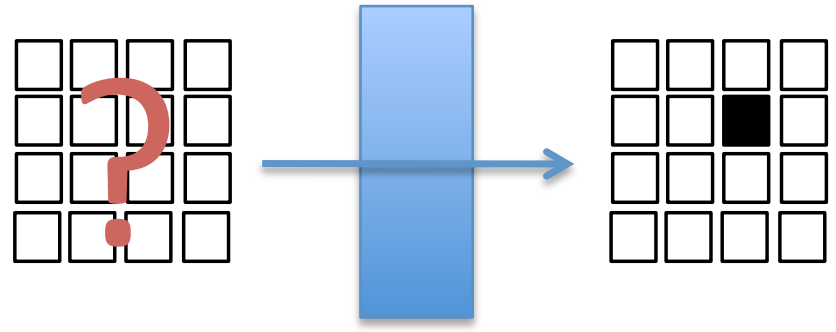

Can $\mathrm{K}$ tell us what input will give a given output?

YES:

interpretation: phase-conjugation

With a phase-only SLM, we have to send

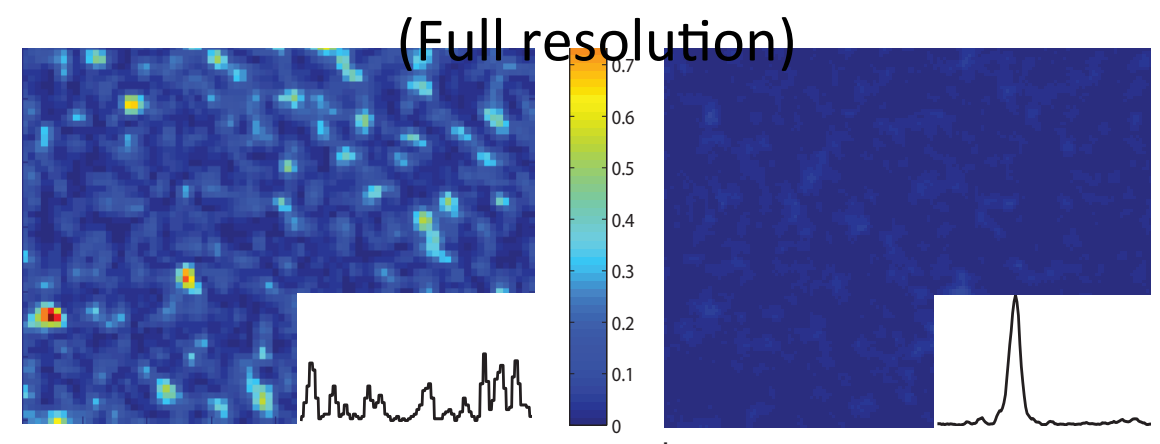

Initial speckle

One point focusing

Multiple point focusing

Ability to focus on any, or many points in one step.

Similar SNR expected as for iterative focusing (here SNR=54 for $\mathrm{N}=256$ pixels) 


\section{The transmission modes}

$\mathrm{K}$ is a NxM complex matrix, not hermitian

A singular value decomposition (SVD) consists in writing $\mathrm{K}=\mathrm{U} \Lambda \mathrm{V}$,

where $\mathrm{U}$ and $\mathrm{V}$ are unitary matrices

$\Lambda$ is a diagonal matrix whose nonzero elements $\lambda_{i}$ are called the singular values of $K$. 


\section{Can we better exploit these channels for imaging ?}

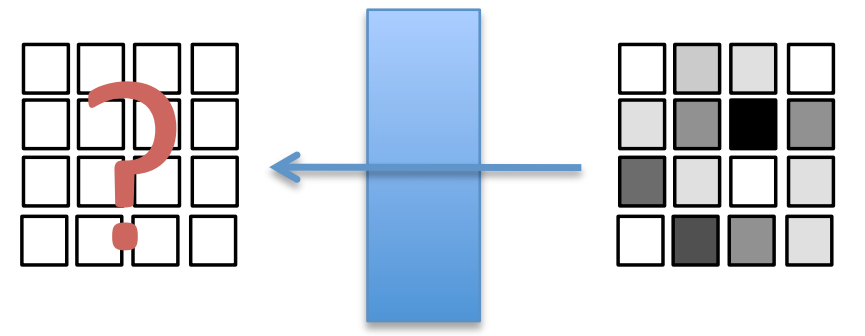

Why not use the obvious $\left(\mathrm{K}^{-1}\right)$ ?

Because noise will degrade the reconstruction for the small singular values of $K$.

(Well-known fact in inverse problems)

There is a solution to this problem of reconstruction in presence of noise, used in telecommunication and in Optical tomography for instance. The optimal operator is :

Renormalization

Without noise :

With a lot of noise : (inversion is optimal)

(phase conjugation is very resilient to noise) 


\section{Experimental setup}

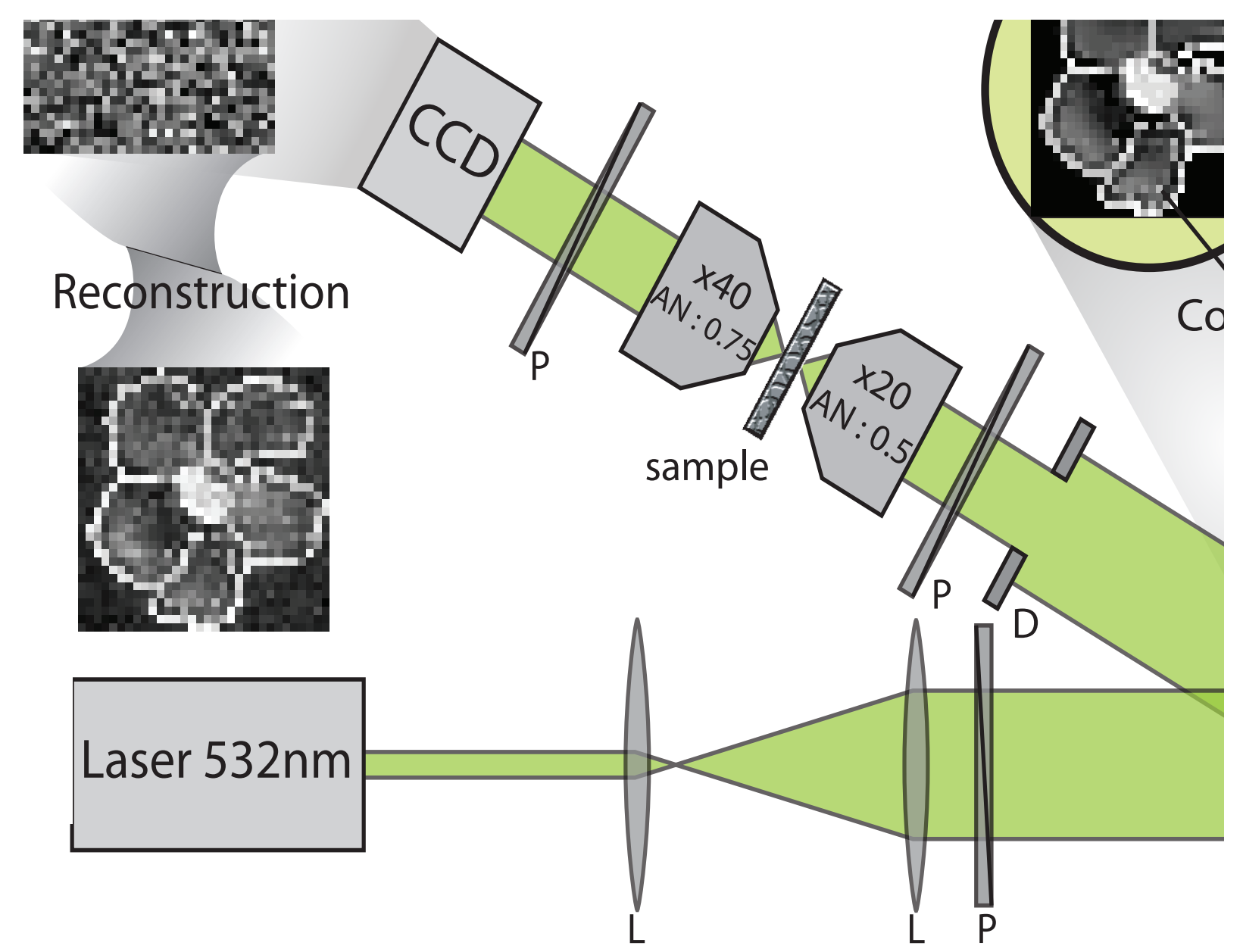

arXiv:1005.0532 


\section{Image transmission}

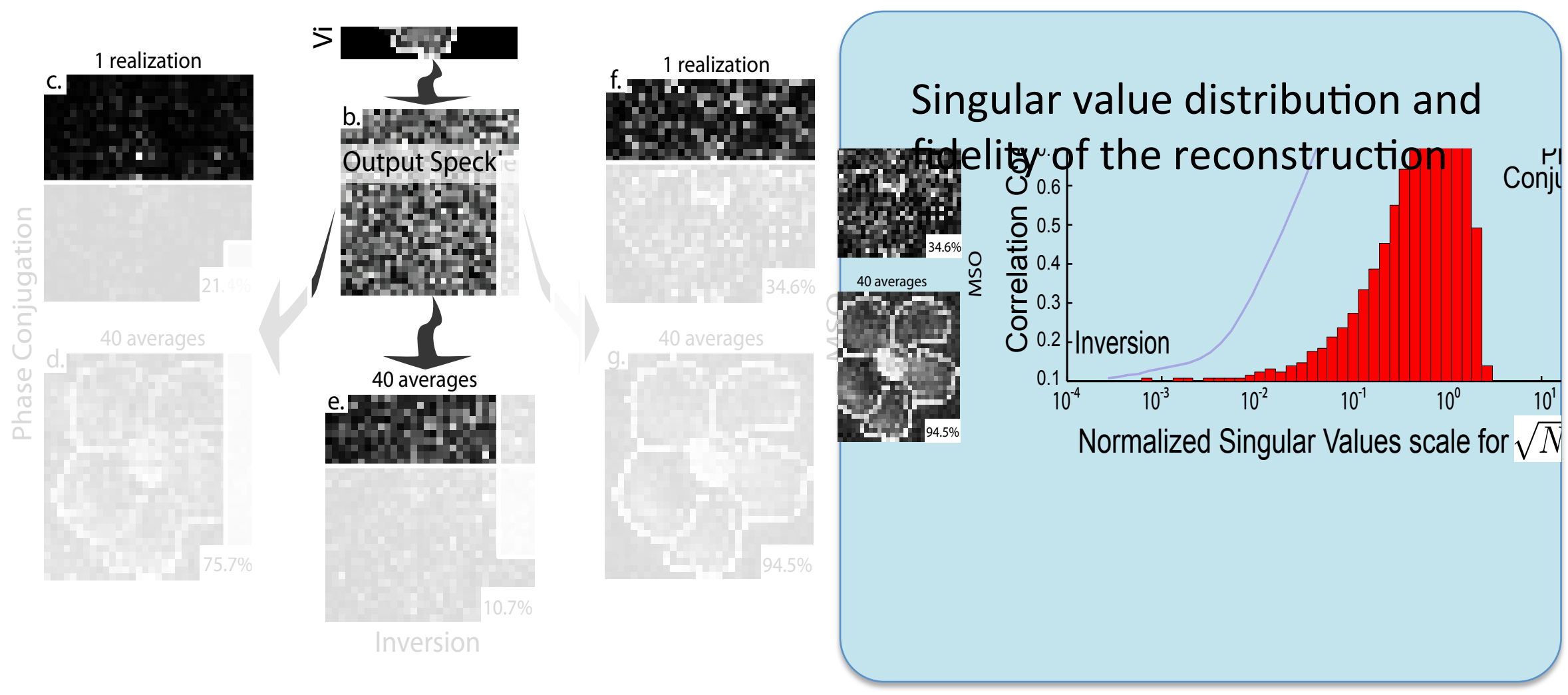

We can tune this parameter 


\section{Can we avoid averaging?}

Increasing the number of

detection pixel

Singular value distribution for increasing $\mathrm{N}_{\text {pixel }}$

-Averaging for free

-Less sensitive to noise

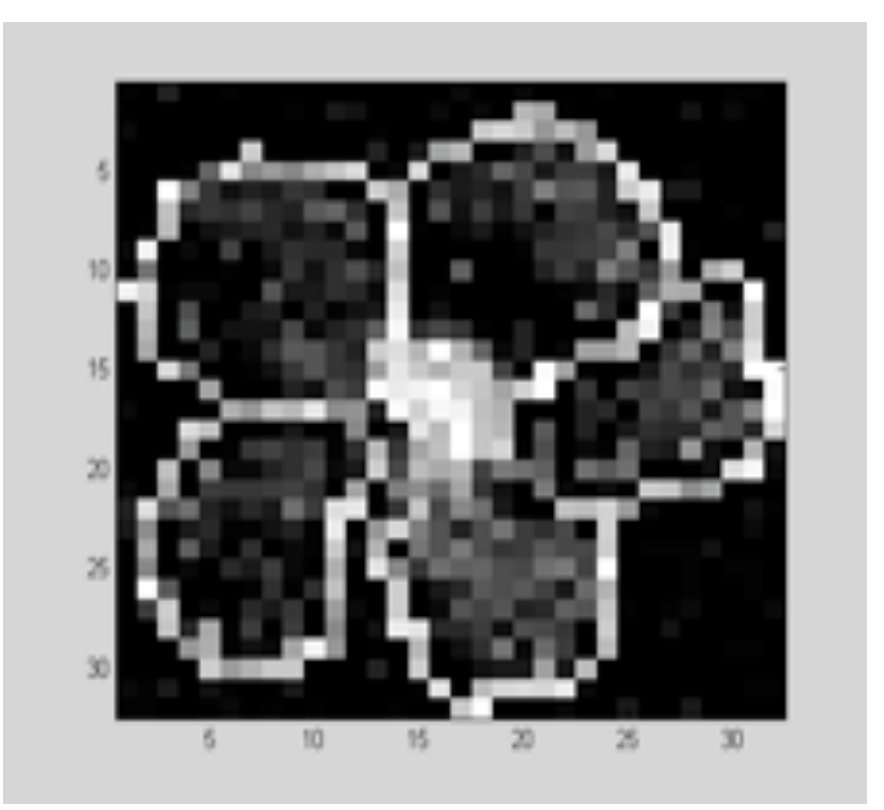

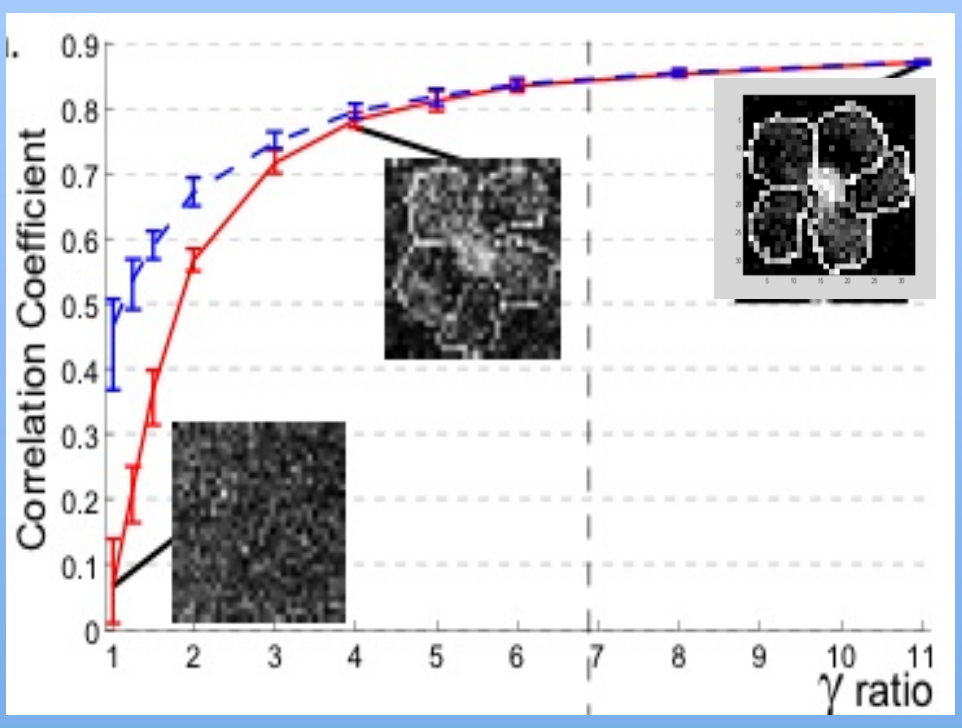

\section{Results:}

No need to average for $>90 \%$ fidelity

Does not increase measurement time

Even inversion work 
USING THE MEMORY EFFECT:

\section{IMAGING WITHOUT TRANSFER MATRIX}
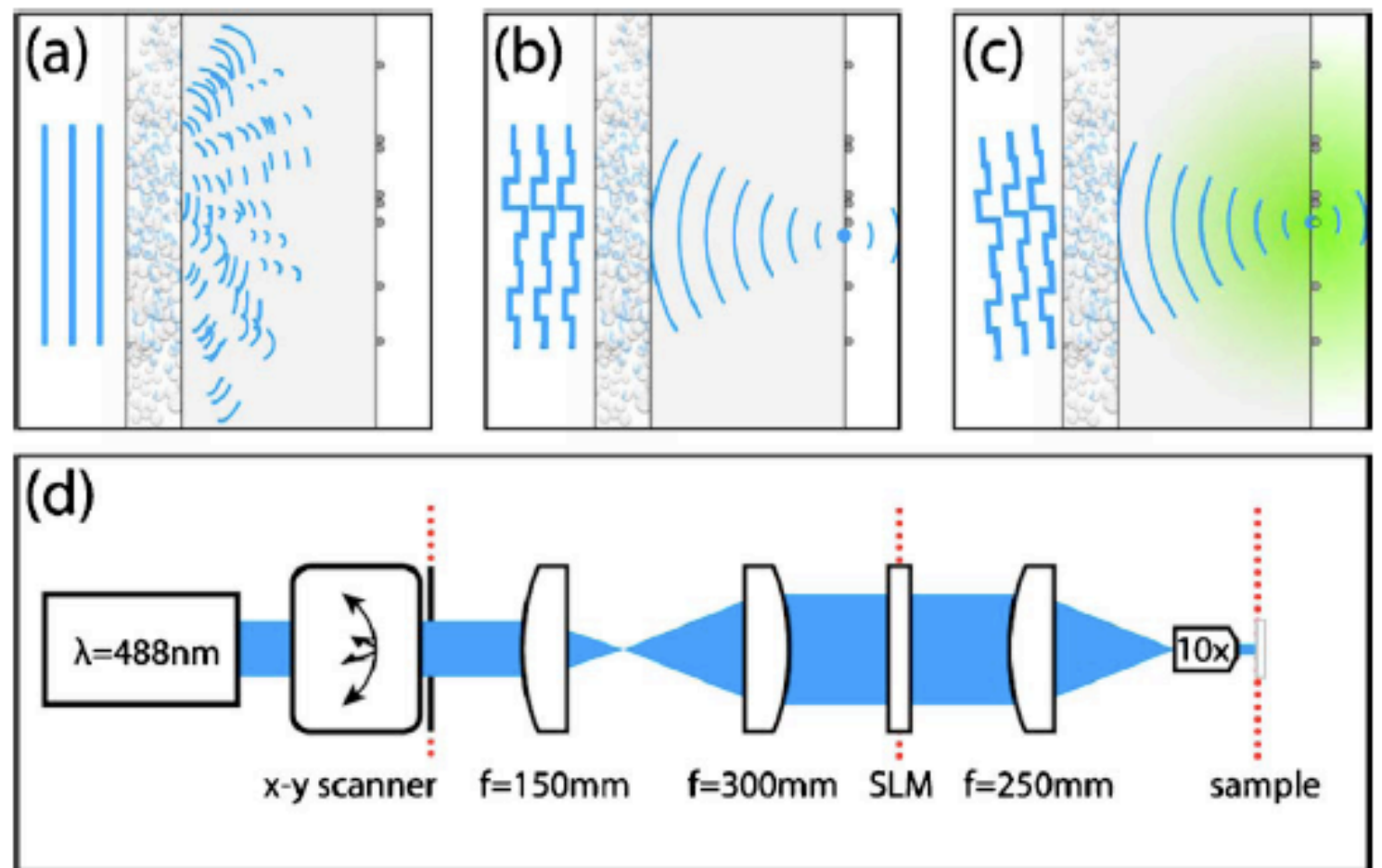

PRINCIPLE OF THE EXPERIMENT:

(a) A turbid layer blocks a fluorescent structure from sight; all incident light is scattered. (b) By use of interferometric focusing (e.g., phase conjugation or wavefront shaping), scattered light is made to focus through the layer. (c) Imaging: the focus follows rotations of the incident beam. The hidden structure is imaged by scanning the focus. (d) Experimental setup. A laser beam is raster scanned, and its wavefront is shaped with a spatial light modulator (SLM). Dotted lines are conjugate planes. For ease of view, the SLM is drawn as a transmissive device, and folding mirrors are omitted.
Scattered light fluorescence microscopy: imaging through turbid layers

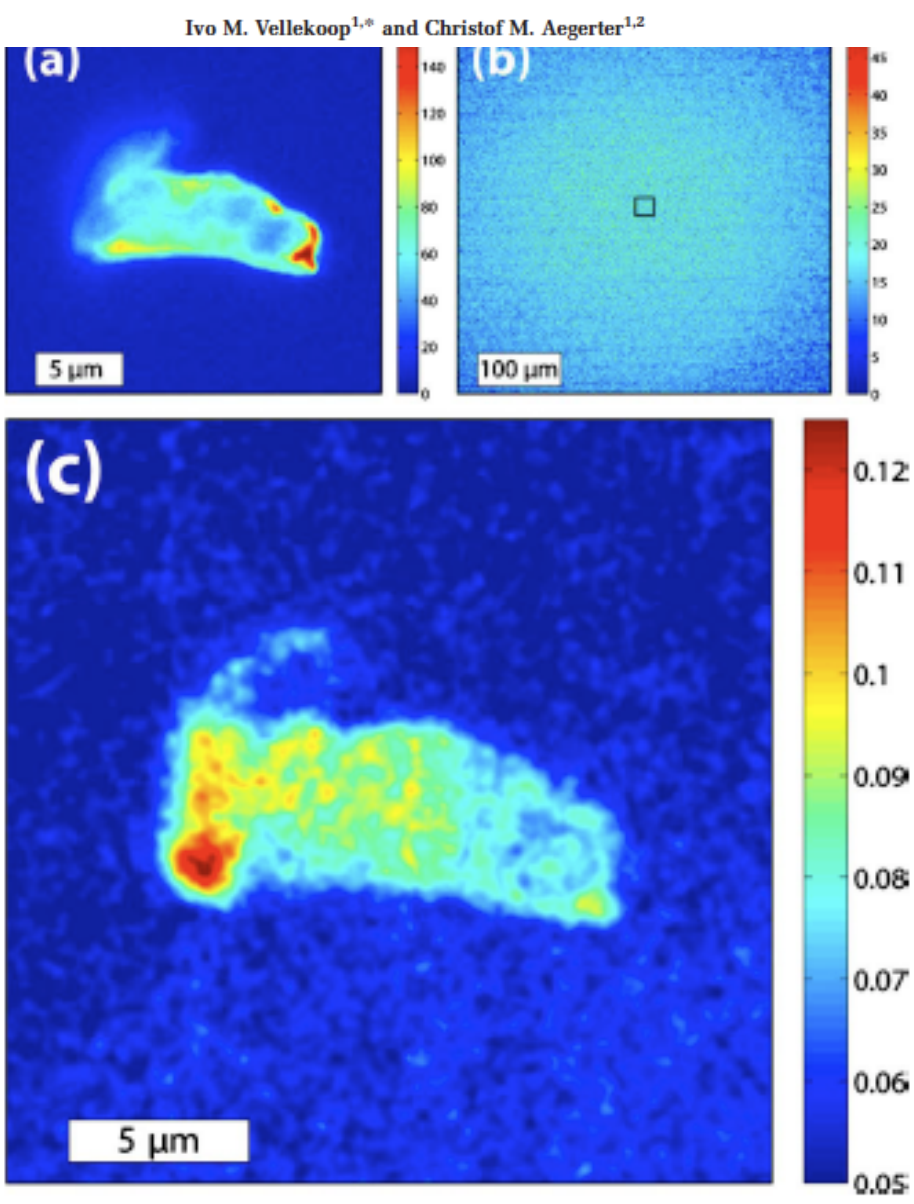

Fig. 2. (Color online) Dense cluster of $200 \mathrm{~nm}$ diameter fluorescent beads. (a) Seen directly (from the back of the sample) with a wide-field fluorescence microscope, no scattering layer between the structure and the microscope. (b) Seen through the 5.1- $\mu \mathrm{m}$-thick scattering layer with a wide-field fluorescence microscope. The structure lies $1 \mathrm{~mm}$ below the layer. Only a diffuse spot, much larger than the fluorescent structure, is visible. Square box, area scanned with the SLF microscope. (c) Seen through the scattering layer with the SLF microscope. The structure is clearly visible at a high resolution. The image was mirrored for ease of comparison with (a). 


\section{Conclusions}

Selecting balistic photons allows a useful "slicing" of random media up to about ten of mean free path (100 dB). Limitations must be understood:

1) Influence of the multiscattered phtons detected by the coherent gate

2) Influence of the large scales heterogeneities (coupling with adaptive optics)

Measurement of the the transmission matrix of a multiple scattering medium.

1) not so difficult nor slow even with current technology

2) An operative tool to manipulate light :

-Application to focusing

-Application to imaging, beyond phase conjugation

3) An important tool to study complex material experimentally

-Demonstration of a universal behavior or RMT : the quarter circle law

- fill a gap between theory and experiments

\section{Perspectives:}

More applications!

More fundamental measurements!

Any critic or suggestion welcome!

REFERENCES : S. Popoff et al, Phys. Rev. Lett. 104, 100601 (2010) \& arXiv:1005.0532 